\title{
Tomato SOBIR1/EVR Homologs Are Involved in Elicitin Perception and Plant Defense Against the Oomycete Pathogen Phytophthora parasitica
}

\author{
Ke-Chun Peng, ${ }^{1}$ Chao-Wen Wang, ${ }^{2}$ Chih-Hang Wu, ${ }^{1}$ Chun-Tzu Huang, ${ }^{1}$ and Ruey-Fen Liou ${ }^{1}$ \\ ${ }^{1}$ Department of Plant Pathology and Microbiology, National Taiwan University, Taipei, Taiwan; ${ }^{2}$ Institute of Plant and Microbial \\ Biology, Academia Sinica, Taipei, Taiwan
}

Submitted 19 December 2014. Accepted 17 February 2015.

\begin{abstract}
During host-pathogen interactions, pattern recognition receptors form complexes with proteins, such as receptor-like kinases, to elicit pathogen-associated molecular patterntriggered immunity (PTI), an evolutionarily conserved plant defense program. However, little is known about the components of the receptor complex, as are the molecular events leading to PTI induced by the oomycete Phytophthora pathogen. Here, we demonstrate that tomato (Solanum lycopersicum) SISOBIRI and SlSOBIRI-like genes are involved in defense responses to Phytophthora parasitica. Silencing of SISOBIRI and SISOBIRI-like enhanced susceptibility to $P$. parasitica in tomato. Callose deposition, reactive oxygen species production, and PTI marker gene expression were compromised in SISOBIRI- and SlSOBIRI-like-silenced plants. Interestingly, $P$. parasitica infection and elicitin (ParA1) treatment induced the relocalization of SISOBIR1 from the plasma membrane to endosomal compartments and silencing of NbSOBIRI compromised ParA1-mediated cell death on Nicotiana benthamiana. Moreover, the SISOBIR1 kinase domain is indispensable for ParA1 to trigger SISOBIR1 internalization and plant cell death. Taken together, these results support the idea of participation of solanaceous SOBIRI/EVR homologs in the perception of elicitins and indicate their important roles in plant basal defense against oomycete pathogens.
\end{abstract}

To prevent infection by pathogens, plants have developed two distinct types of immunity: i) pathogen-associated molecular pattern (PAMP)-triggered immunity (PTI) and ii) effectortriggered immunity (ETI) (Dodds and Rathjen 2010; Jones and Dangl 2006). PAMPs (also known as microbe-associated molecular patterns [MAMPS]), derived from microbial pathogens, are conserved molecular structures that are recognized by pattern recognition receptors (PRR) and elicit the first layer of plant immunity, i.e., PTI. On the other hand, some adapted plant pathogens can produce effectors to suppress PTI and thus promote disease development. Through the arms race with

Nucleotide sequence data is available in the GenBank database under accession numbers KF268115 (SISOBIR1), KF977196 (SISOBIR1-like), and KF998581 (NbSOBIR1).

Corresponding author: R.-F. Liou; E-mail: rfliou@ntu.edu.tw; Telephone: +886-2-3366-5208; Fax: +886-2-2362-0271

*The $\boldsymbol{e}$-Xtra logo stands for "electronic extra" and indicates that nine supplementary figures and one supplementary table are published online.

○ 2015 The American Phytopathological Society pathogens, plants have evolved resistance $(\mathrm{R})$ proteins to recognize cognate effectors or effector-mediated alteration of host targets and, thereby, activate ETI (Dodds and Rathjen 2010; Jones and Dangl 2006).

Most plant PRR are members of the receptor-like kinase (RLK) or receptor-like protein (RLP) family, implicated in multiple physiological programs, including plant development and immunity to microbial infection (Morillo and Tax 2006; Shiu and Bleecker 2003). In Arabidopsis thaliana, the most studied PRR are FLAGELLIN SENSING 2 (FLS2) and EF-TU RECEPTOR (EFR), both leucine-rich repeat (LRR)-RLK responsible for perceiving bacterial PAMPs flg22 (derived from flagellin) and elf18/elf26 (derived from elongation factor Tu), respectively (Gómez-Gómez and Boller 2000; Zipfel et al. 2004, 2006). As well, CHITIN ELICITOR RECEPTOR KINASE 1, a Lysine motif-RLK, recognizes fungal chitin and mediates resistance to fungal pathogens (Miya et al. 2007). When PRR perceive their cognate PAMPs, downstream defense signaling pathways are activated that involve ion fluxes, activation of calcium-dependent protein kinases and mitogen-activated protein kinases, reactive oxygen species (ROS) production, callose deposition, and defense gene induction (Altenbach and Robatzek 2007; Boller and Felix 2009; Zipfel 2009). As a consequence, plants display basal resistance to a broad range of pathogens.

Recent studies to elucidate molecular events immediately after flg22 perception indicated that FLS2 forms a heterodimer with BRASSINOSTEROID (BR) INSENSITIVE 1 (BRI1)ASSOCIATED RECEPTOR KINASE 1 (BAK1; also known as SOMATIC EMBRYOGENESIS RLK3 [SERK3]), which was first identified due to its interaction with BRI1, a receptor of the plant hormone BR (Chinchilla et al. 2007; Heese et al. 2007). Upon perception of BR, BAK1 forms a heterodimer with BRI1, which is followed by a rapid reciprocal transphosphorylation of cytoplasmic kinase domains and activation of a downstream signaling pathway (Wang et al. 2008). Null bakl mutant plants are hyposensitive to BR, which indicates that BAK1 acts as a positive regulator of the BRI1 pathway (Chinchilla et al. 2007; Heese et al. 2007). In addition to binding with BRI1, BAK1 forms receptor complexes with FLS2 and EFR in a ligand-dependent manner and is also required for responses triggered by other PAMPs, such as lipopolysaccharides, peptidoglycans, and HrpZ, as well as INF1, an elicitin identified in Phytophthora infestans (Chinchilla et al. 2007; Heese et al. 2007; Shan et al. 2008). Therefore, BAK1 is considered a central regulator of plant basal immunity (Chinchilla et al. 2009). Two additional RLK function as regulators of defense responses in A. thaliana, BAK1-interacting RLK (BIRl) and Suppressor of 
BIR1-1/Evershed (SOBIRI/EVR; hereafter called AtSOBIR1) (Gao et al. 2009). Moreover, SERK1 and BAK1-LIKE 1 (BKK1; also known as SERK4), both involved in regulating cell death and senescence (He et al. 2007), were found to be components of the ligand-induced FLS2 and EFR receptor complexes and required for FLS2- and EFR-dependent responses, which reinforces the idea that PRR functions as part of multiprotein complexes at the plasma membrane with the triggering of plant basal immunity (Monaghan and Zipfel 2012; Roux et al. 2011). Of note, FLS2 undergoes ligand-induced endocytosis and subsequent degradation upon elicitation by flg22 (Geldner and Robatzek 2008; Robatzek et al. 2006). Similarly, LeEix2 receptor is internalized in reponse to treatment with the ethyleneinducing xylanase (EIX) from Tichoderma viride, a potent elicitor of plant defense responses (Bar and Avni 2009). These results highlight the important role of receptor-mediated endocytosis in the regulation of plant defense signaling (Bar and Avni 2014; Leborgne-Castel et al. 2010).

Oomycetes belong to a phylogenetically distinct group of eukaryotic microorganisms that resemble true fungi in morphologic features and pathogenic life style (Baldauf et al. 2000). Members of the genus Phytophthora are of special interest because many of them cause devastating diseases in economically important crops and ornamental plants (Erwin and Ribeiro 1996; Kamoun et al. 2014). PAMPs identified in genus Phytophthora thus-far include CBD (derived from cellulose binding elicitor lectin [CBEL]) of Phytophthora parasitica (Gaulin et al. 2006; Mateos et al. 1997), Pep-13 (derived from calcium-dependent transglutaminase GP42) of Phytophthora sojae (Brunner et al. 2002; Nürnberger et al. 1994), and elicitins such as INF1 (Kamoun et al. 1997). Elicitins are a family of structurally related extracellular proteins that are secreted by all tested Phytophthora and Pythium species (Ponchet et al. 1999). These proteins induce the hypersensitive response (HR) and other defense responses in a limited range of dicot plants, including Nicotiana spp. (Kamoun et al. 1993a and b, 1997; Ricci et al. 1989). For example, ParA1, a close homolog of INF1 identified in $P$. parasitica, induces a necrotic HR on tobacco leaves (Kamoun et al. 1993a). INF1 elicits HR cell death and ROS production in Nicotiana benthamiana. Knocking down the expression of SERK3-like abrogated INF1-induced cell death (Heese et al. 2007). On the other hand, silencing of the $N$. benthamiana homologs of $S E R K 3 / B A K 1$, including both $N b S E R K 3 A$ and $N b S E R K 3 B$, enhanced plant susceptibility to $P$. infestans and reduced the cell death responses triggered by INF1 in $N$. benthamiana (Chaparro-Garcia et al. 2011). INF1 also interacted with a lectin-like receptor kinase, NbLRK1, and downregulation of this gene delayed INF1-mediated HR cell death (Kanzaki et al. 2008). Nonetheless, our current knowledge about the nature of elicitin receptors and components of the receptor complex remains very limited, not to mention other LRR-RLK that might be involved in elicitin-mediated cell death and plant basal defense against Phytophthora infection.

In attempts to identify tomato genes that are involved in plant immunity against $P$. parasitica, we performed microarray analyses and found a variety of genes that are upregulated in response to pathogen infection, including one that encodes SlSOBIR1, a tomato (Solanum lycopersicum) homolog of AtSOBIR1. Just recently, SISOBIRI/EVR and its close homolog SlSOBIRl-like were found to interact with both Cf-4 and Ve1 in planta and were required for HR and for plant resistance to Cladosporium fulvum and Verticillium dahliae mediated by these two RLP (Liebrand et al. 2013). Here, we demonstrate that SISOBIRI and SISOBIRl-like are involved in tomato basal defense against $P$. parasitica infection. Notably, both pathogen infection and ParA1 treatment induced the endocytosis of SISOBIR1. Furthermore, a SOBIRI/EVR homolog of $N$. benthamiana, NbSOBIR1, is required for full induction of ParA1mediated cell death. These results imply the participation of SISOBIR1 in the formation of the receptor complex, which mediates elicitin perception and defense signaling against oomycete pathogen infection.

\section{RESULTS}

\section{Molecular cloning and sequence analysis of SISOBIRI and SlSOBIRI-like.}

To identify tomato genes involved in the plant defense against $P$. parasitica, we performed microarray analyses and found various genes upregulated in response to pathogen infection (R. F. Liou unpublished data), including one that encodes a putative RLK, tomato gene model Solyc06g071810.1.1 (unigene SGN-U565512; corresponding to probe ID Les.5205.1. S1_at [Affymetrix]). By searching the Sol Genomics Network (SGN), we found a close homolog with about $80 \%$ nucleotide identity with this gene, Solyc03g111800.1.1 (SGN-U568730). These two genes were reported recently by Liebrand et al. (2013) and were named SISOBIRI (Solyc06g071810) and SISOBIRIlike (Solyc03g111800), respectively.

The cDNA fragments for both genes were cloned with mRNA from tomato (cv. Summer Sweet) as the template (GenBank accession numbers: KF268115 [SlSOBIRl] and KF977196 [SlSOBIR1-like]). When compared with the sequences in the SGN database, the amino acid sequence of KF268115 is identical to the SlSOBIRl sequence, whereas KF977196 possesses an extra segment of 50 amino acid residues when compared with SlSOBIRl-like (Supplementary Fig. S1A). BLASTP analysis with the National Center for Biotechnology Information and SGN websites revealed the presence of respective homologs for SISOBIRI and SISOBIRIlike in Solanum tuberosum, with identity of $92.7 \%$ between Sotub06g029250.1.1 and SlSOBIR1 and 95.6\% between Sotub03g023250.1.1 and SlSOBIRl-like. N. benthamiana also contains two homologs, namely, NbSOBIRl (NbS00037616 g0014.1) and NbSOBIR1-like (NbS00006092g0015.1). We have determined the cDNA sequence of NbSOBIR1 (KF998581) and found that it is identical to that shown in the database. However, we failed to detect any expression of NbSOBIRl-like. There is only one SOBIRl homolog of N. tabacum in GenBank, AB073628, which is close to NbSOBIRl, as revealed by phylogenetic analysis.

\section{Transcription of SlSOBIRI and SlSOBIRI-like is induced in response to $P$. parasitica infection and salicylic acid (SA) treatment.}

To confirm the extent to which SISOBIRI and SISOBIRl-like are induced by $P$. parasitica infection, we analyzed their transcriptional expression in response to pathogen inoculation. Compared with mock-inoculated controls, the expression of SISOBIRl was induced highly (24-fold) in tomato leaves at $1 \mathrm{~h}$ postinoculation (hpi) and to a lesser extent at 3 and 6 hpi but upregulated again at $12 \mathrm{hpi}$ (Fig. 1A). In contrast, the expression of SISOBIRl-like was significantly upregulated only at 12 hpi.

To test whether plant-hormone signaling cascades regulate the transcription of SISOBIRI and SlSOBIRI-like, we treated plants with different plant hormones and analyzed their expression. The expression of both SISOBIRI and SISOBIRl-like was induced at $3 \mathrm{~h}$ posttreatment (hpt) with $\mathrm{SA}$ and was downregulated to a background level at 6 hpt (Fig. 1B). With ethylene (ET) treatment, SISOBIRI was significantly induced at $3 \mathrm{hpt}$ (Fig. 1C), whereas SlSOBIRl-like was downregulated 
at $6 \mathrm{hpt}$. In contrast, treatment with methyl jasmonate (MeJA) downregulated the expression of both SISOBIRI and SISOBIRI-like (Fig. 1D). Thus, the expression of SISOBIRI and SISOBIRl-like was induced by SA but downregulated by JA. With ET treatment, only SISOBIRl was induced.

\section{Silencing of SISOBIRI and SISOBIRI-like enhances plant susceptibility to $P$. parasitica.}

To determine whether SISOBIRI and SISOBIRl-like are involved in disease resistance, we silenced the expression of SlSOBIRl or SlSOBIRl-like, alone or together, in tomato plants by Tobacco rattle virus (TRV)-mediated gene silencing and, then, challenged plants with $P$. parasitica. Four weeks after virus inoculation, plants were inoculated with zoospores of $P$. parasitica and were examined for the development of disease symptoms as well as the expression levels of SISOBIRI and SlSOBIR1-like. In TRV-SlSOBIR1-infected tomato plants, the expression of SlSOBIRl but not SISOBIR1-like was downregulated in systemic leaves as compared with control plants (TRV) (Supplementary Fig. S2A). Similarly, in plants infected with TRV-SISOBIRl-like, only SISOBIRl-like was downregulated. In contrast, in plants infected with TRV-SlSOBIRI \&SISOBIRl-like, containing a conserved sequence of SISOBIRI and SISOBIRl-like, both genes were downregulated. With silencing of SISOBIRI or SISOBIR1-like individually, plants became more susceptible to infection by $P$. parasitica, as revealed by the appearance of disease symptoms (Fig. 2A) and disease severity scores (Fig. 2B). To further confirm the effect of SOBIRI silencing on $P$. parasitica colonization, we employed quantitative polymerase chain reaction (qPCR) to analyze the accumulation of $P$. parasitica WS21 on the inoculated plants. WS21 encodes a ribosomal protein (Yan and Liou 2006) and here serves as an indicator of pathogen biomass. The biomass of P. parasitica on SISOBIRl-silenced plants was more abundant than that of the control plants with the empty vector (TRV) at both 48 and $72 \mathrm{hpi}$, whereas significant difference was detected for the SISOBIRl-like-silenced plants only at 72 hpi (Fig. 2C). When both genes were silenced simultaneously, the plants became even more susceptible to $P$. parasitica infection, as revealed by the enhanced disease symptoms (Fig. 2A), disease severity scores (Fig. 2B), and the highly increased level of pathogen biomass at both 48 and 72 hpi (Fig. 2C). Thus, both SISOBIRl and SISOBIR1like are required for the basal disease resistance of tomato to $P$. parasitica.

Downregulation of SISOBIRI and SISOBIRI-like causes reduced plant defense response against $P$. parasitica.

To further determine whether SISOBIRI and SlSOBIRl-like regulate plant defense responses during pathogen infection, we examined tomato leaves for ROS accumulation, callose deposition, and expression of PTI marker genes after TRVmediated gene silencing and pathogen inoculation. Control plants infected by $P$. parasitica showed prominent production of $\mathrm{H}_{2} \mathrm{O}_{2}$ at 3 hpi (TRV) (Fig. $3 \mathrm{~A}$ and $\mathrm{C}$ ), accompanied by callose deposition at 12 hpi (TRV) (Fig. 3B and D). The expression of PTI marker genes, including Pti-5, WRKY28, Gras2, and Lrr22, was significantly induced at 6 hpi (Supplementary

B
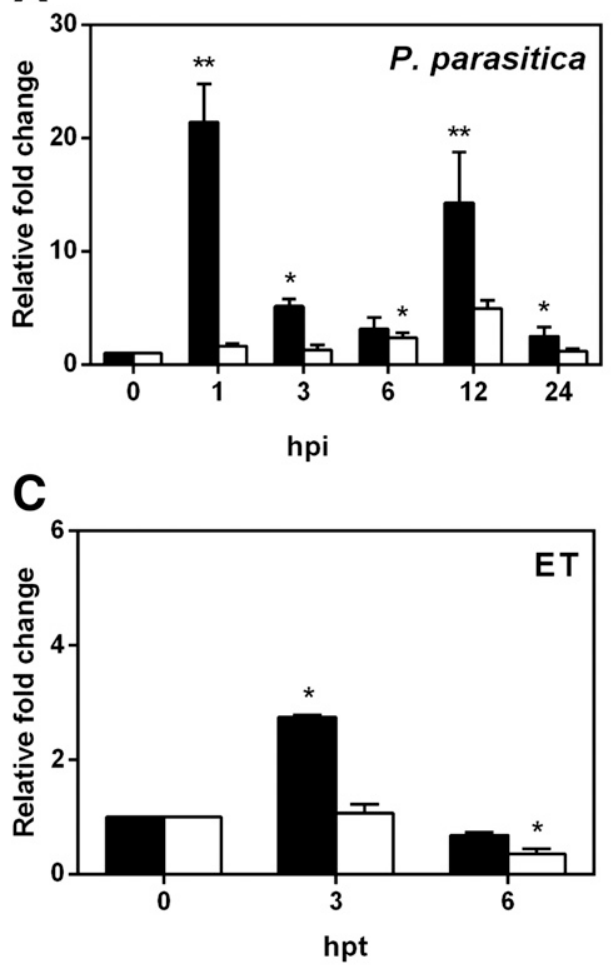

SISOBIR1

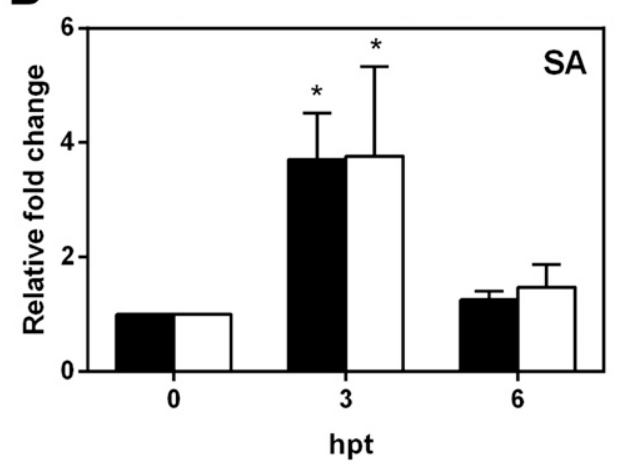

D

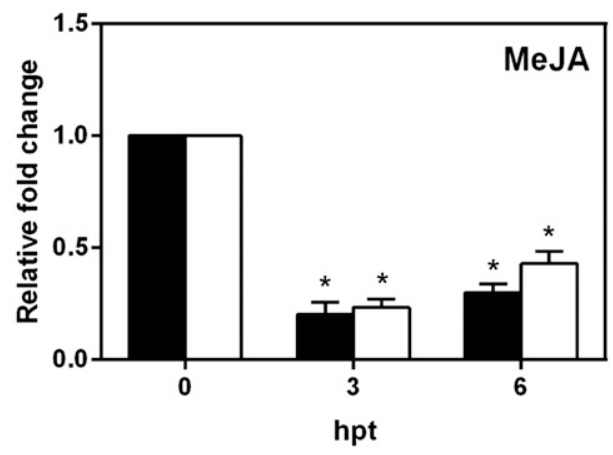

SISOBIR1-like

Fig. 1. Expression of SISOBIRI and SISOBIRl-like genes is induced in response to infection by Phytophthora parasitica and treatment with plant hormones. After pathogen inoculation or hormone treatment of 4 -week-old tomato (Solanum lycopersicum cv. Summer Sweet), total RNA isolated from the leaves were analyzed by quantitative reverse transcription-polymerase chain reaction. eIF5A-4 was used as an internal control. Data from three independent experiments are presented as mean ( \pm standard deviation) fold change relative to time 0 . An asterisk (*) indicates $P<0.05$, two (**) indicate $P<0.01$ by Student $t$ test. hpi $=$ hours postinoculation with pathogen; hpt $=$ hours posttreatment with plant hormone. A, Inoculation with zoospores of $P$. parasitica; $\mathbf{B}$, Treatment with salicylic acid (SA), C, ethylene (ET), and D, methyl jasmonate (MeJA). 
Fig. S3). In contrast, plants with silencing of one or both SISOBIRI and SISOBIRl-like showed significantly reduced $\mathrm{H}_{2} \mathrm{O}_{2}$ production (Fig. 3A and $\mathrm{C}$ ) and callose deposition (Fig. 3B and D). Moreover, silencing of SISOBIRI reduced expression of Pti-5, WRKY28, and Gras 2 , and simultaneous silencing of both genes reduced expression of Pti-5 and WRKY28 (Fig. 3E to $\mathrm{G}$ ), with no change in expression of Lrr22 (Fig. 3H). At this time point of infection, the expression of one or both SISOBIRI and SlSOBIRl-like was still suppressed by the silencing constructs. Therefore, both SISOBIRI and SISOBIRl-like play essential roles in triggering plant basal defense responses to $P$. parasitica infection, although their roles for the regulation of PTI marker genes may differ.

\section{$P$. parasitica inoculation and ParA1 treatment induce the endocytosis of SISOBIR1.}

Receptor-mediated endocytic trafficking pathways play important roles for PAMP perception and cellular responses during pathogen attack (Geldner and Robatzek 2008; LeborgneCastel et al. 2010). A recent report has established that SISOBIRI and SISOBIRl-like encode transmembrane domain-containing, receptor-like protein kinases that localize to the plasma membrane (Liebrand et al. 2013). To study functions of these proteins during
A
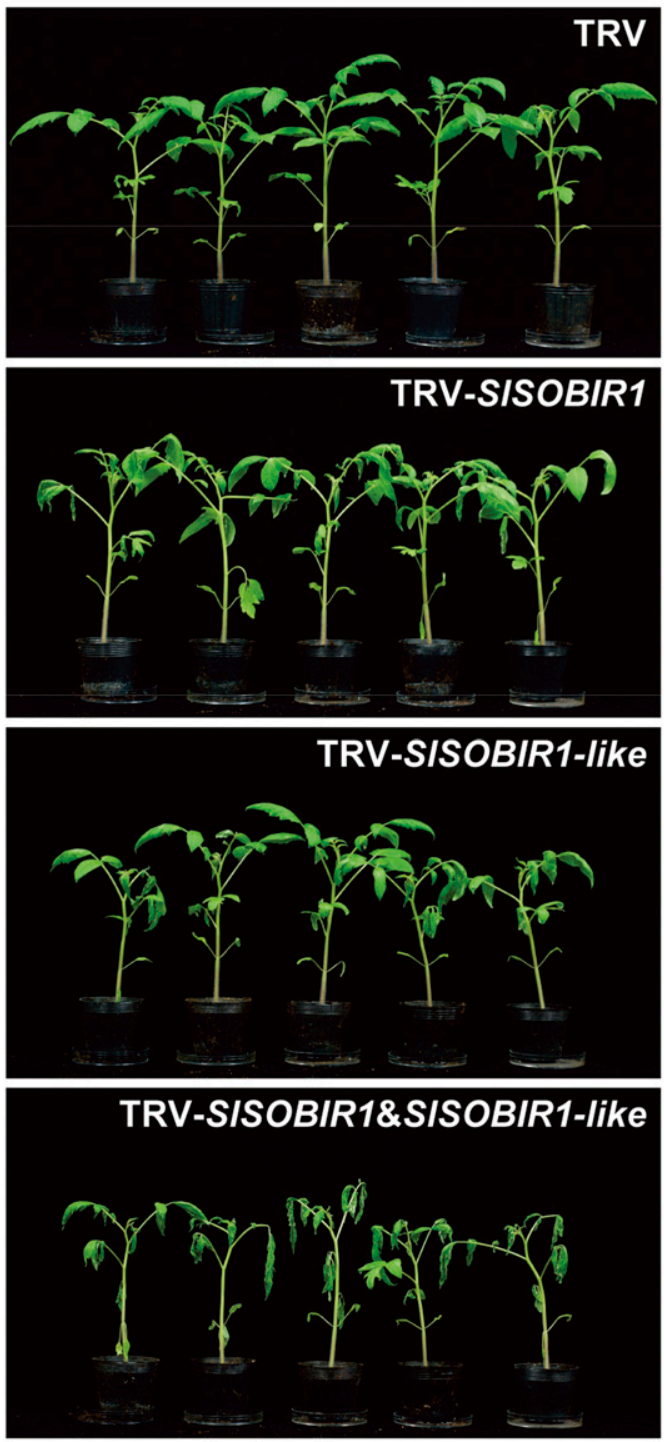

B
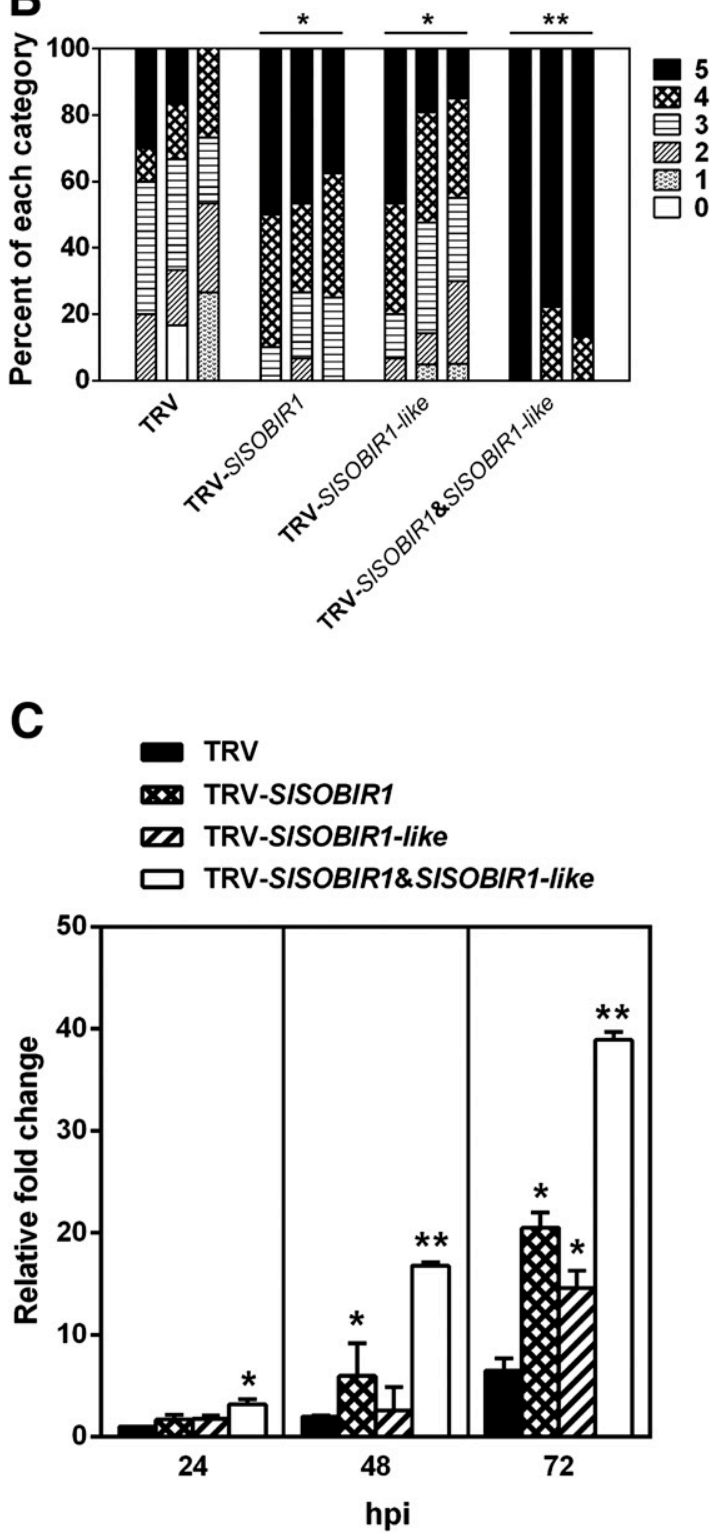

Fig. 2. Silencing of SISOBIR1 and SlSOBIR1-like genes enhances tomato susceptibility to Phytophthora parasitica. A, Downregulation of one or both SISOBIR1 and SISOBIR1-like enhances tomato susceptibility to $P$. parasitica. At 4 weeks post-agroinfection for Tobacco rattle virus (TRV)-mediated gene silencing of one or both SISOBIRI and SISOBIR1-like, tomato plants were inoculated with zoospores of P. parasitica and were examined for disease development. Plants infiltrated with the empty vector (TRV) served as a control. Images were obtained at $36 \mathrm{~h}$ postinoculation (hpi). Experiments were repeated three times, each with 10 plants. B, Disease index of tomato plants. Disease severity was scored on a scale from 0 to 5 , according to symptoms developed on tomato plants: 0 , healthy, no water-soaking lesions; $1,<25 \%$ lesions; 2,25 to $50 \%$ lesions; 3,50 to $75 \%$ lesions; 4,75 to $100 \%$ lesions; and 5, complete wilting. One asterisk (*) indicates $P<0.05$, two (**) indicate $P<0.01$ by Wilcoxon rank-sum test. C, Quantification of $P$. parasitica biomass by quantitative polymerase chain reaction (qPCR). After pathogen inoculation of tomato plants silenced in one or both SlSOBIR1 and SlSOBIRI-like, DNA was isolated from systemic leaves at 24, 48, and 72 hpi, respectively. The quantity of P. parasitica WS21 and tomato elf5A-4 was determined by qPCR. Data of P. parasitica WS21 were normalized with tomato eIf5A-4 and are presented as mean ( \pm standard deviation) fold change relative to plants infiltrated with the empty vector (TRV) at 24 hpi from three independent experiments. One asterisk (*) indicates $P<0.05$, two (**) indicate $P<0.01$ by Student $t$ test. 
A
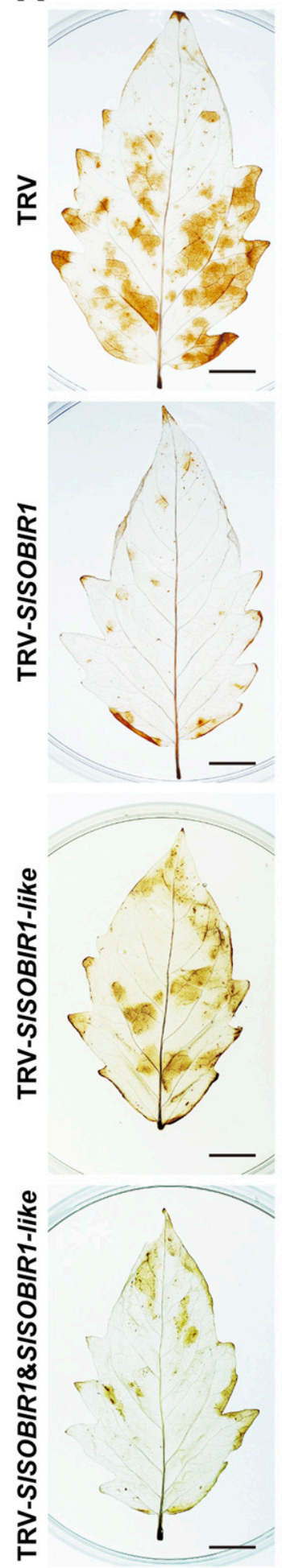

B
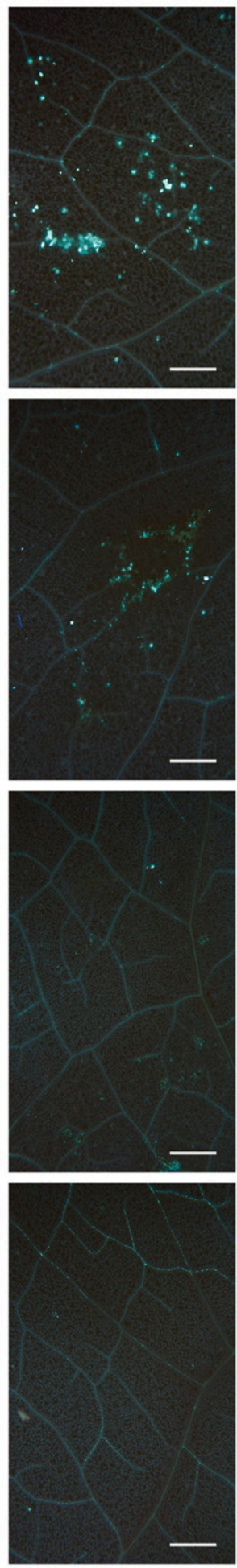

C

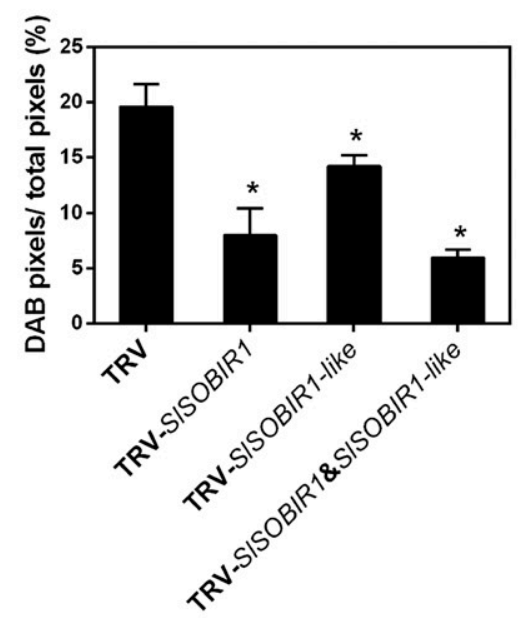

E

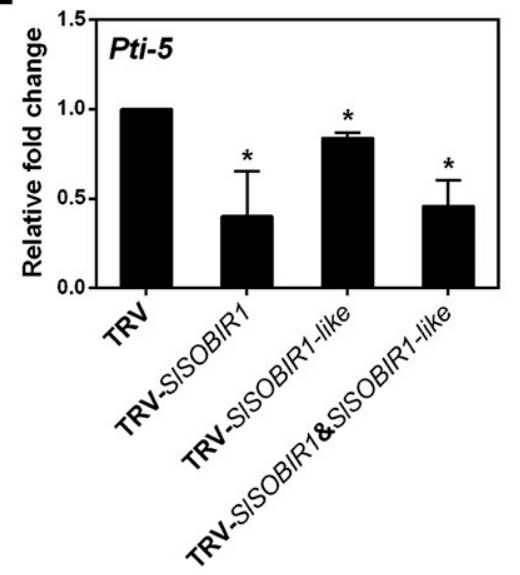

G

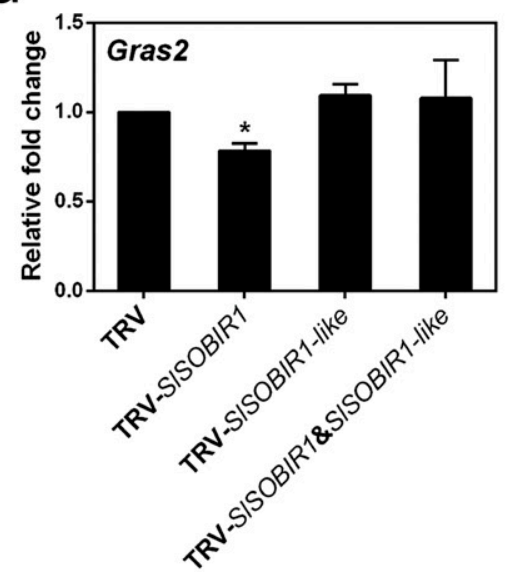

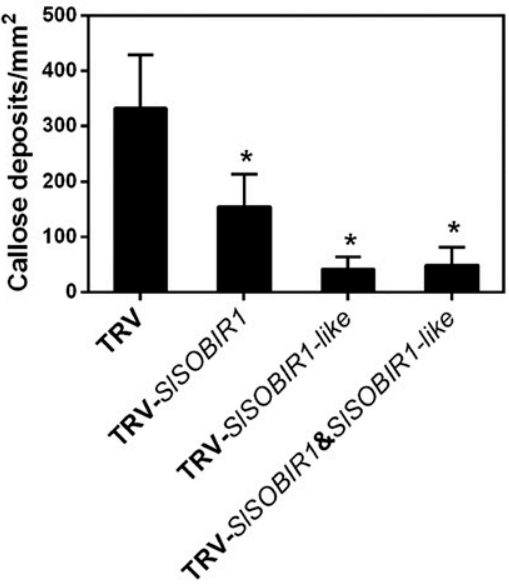

F

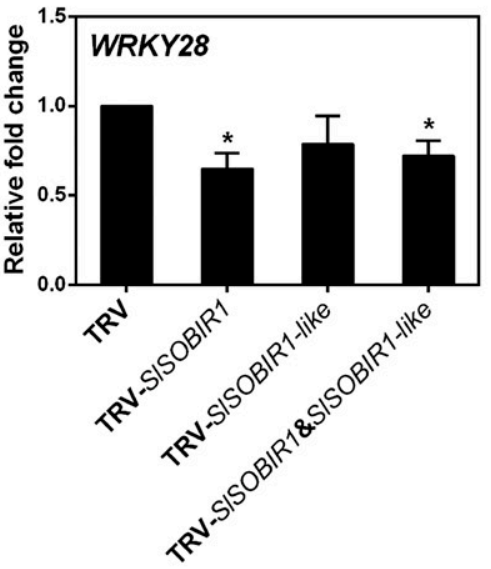

H

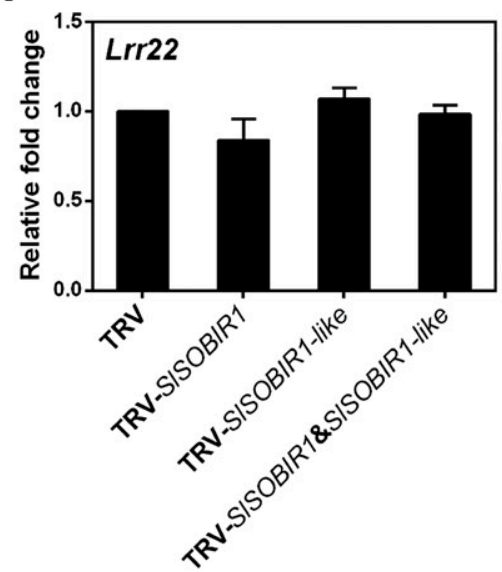

Fig. 3. Downregulation of SISOBIRI and SISOBIR1-like genes attenuates tomato defense responses to Phytophthora parasitica. At 4 weeks post-agroinfection for Tobacco rattle virus (TRV)-mediated gene silencing of one or both SISOBIRI and SISOBIRI-like, tomato plants were inoculated with zoospores of $P$. parasitica and were then subjected to 3,3'-diaminobenzidine (DAB) staining, aniline blue staining, and quantitative reverse transcription-polymerase chain reaction (qRT-PCR) analysis. Plants infiltrated with the empty vector (TRV) served as a control. A, Staining with DAB at $3 \mathrm{~h}$ postinoculation (hpi) to detect $\mathrm{H}_{2} \mathrm{O}_{2}$ accumulation. Bar $=1 \mathrm{~cm}$. B, Staining with aniline blue at $12 \mathrm{hpi}$ to detect callose deposition. The images were captured by fluorescence microscopy. Bar $=25 \mu \mathrm{m}$. C, Quantification of DAB staining. Values are mean ( \pm standard deviation [SD]) from three independent experiments (each with 10 leaves). Asterisks $(*)$ indicate $P<0.05$ by Student $t$ test compared with TRV. D, Quantification of aniline blue staining. Values are mean ( \pm SD) from three independent experiments. Asterisks $(*)$ indicate $P<0.05$ by Student $t$ test. $\mathbf{E}$ to $\mathbf{H}, \mathrm{qRT}-\mathrm{PCR}$ analysis of defense genes. Total RNAs isolated from inoculated plants at 6 hpi were analyzed for the expression of Pti-5 (E), WRKY28 (F), Gras2 (G), and Lrr22 (H), with eIF5A-4 as the internal control. Values are mean ( \pm SD) fold change relative to empty vector (TRV) inoculation from three independent experiments. Asterisks (*) indicate $P<0.05$ by Student $t$ test. 
$P$. parasitica infection, we expressed green fluoresent protein (GFP)-fusion proteins of SlSOBIR1- and SlSOBIRl-like on $N$. benthamiana by agroinfiltration. Confocal microscopy results revealed that SISOBIR1-GFP localized to the plasma membrane, as visualized by colocalization with the staining of the lipophilic
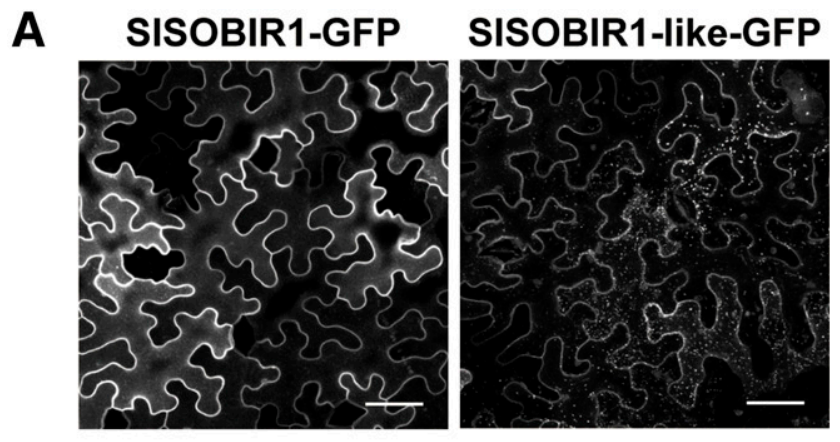

B
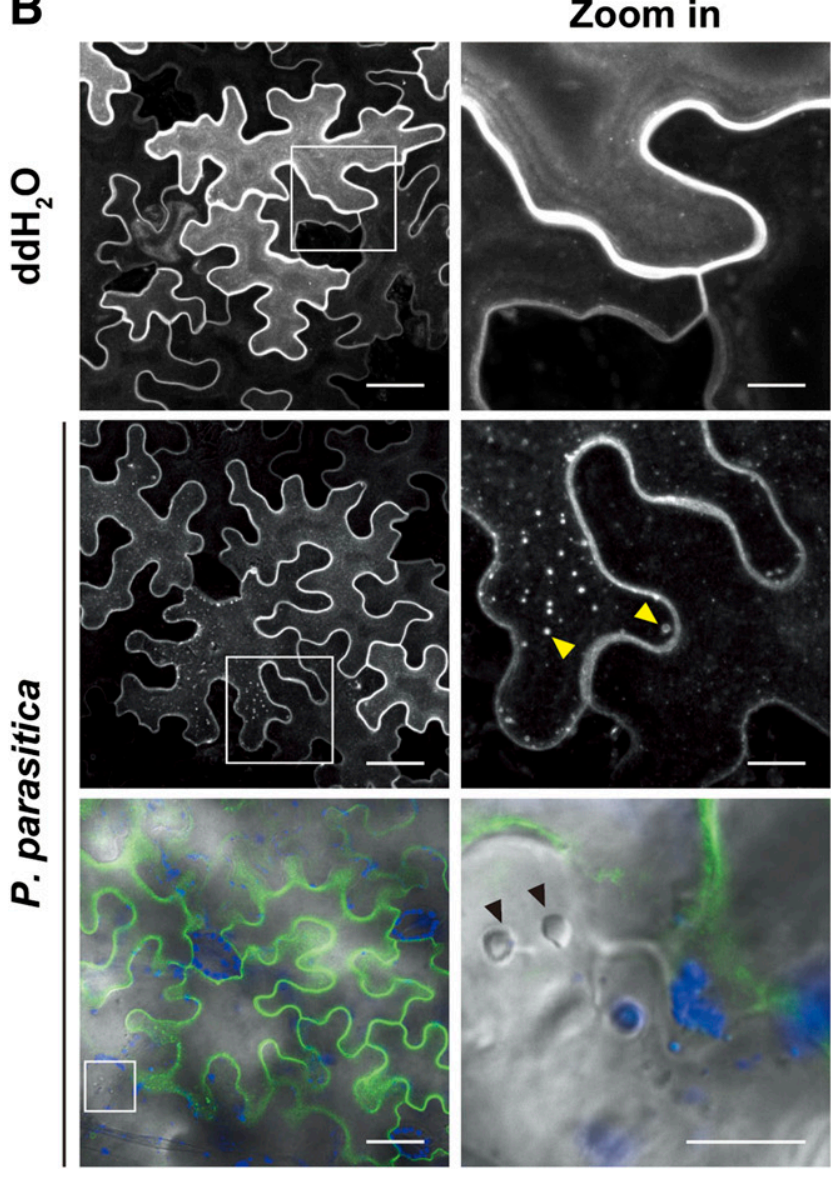

Fig. 4. SISOBIR1-GFP moved to vesicle-like structures in response to Phytophthora parasitica infection. A, Subcellular localization of SISOBIR1GFP and SISOBIR1-like-GFP. At 23 h post-agroinfiltration, Nicotiana benthamiana leaves were examined under a confocal microscope. Bar = $25 \mu \mathrm{m}$. B, Subcellular localization of SISOBIR1-GFP in response to Phytophthora parasitica infection. At $23 \mathrm{~h}$ post-agroinfiltration for expressing SISOBIR1-GFP, $N$. benthamiana leaves were inoculated with zoospores of P. parasitica (or double-distilled $\mathrm{H}_{2} \mathrm{O}$ as a control) and were examined under a confocal microscope at $3 \mathrm{~h}$ postinoculation. The first and second rows show the green fluorescent protein (GFP) images, and the bottom row shows an overlay of GFP with images recorded under red light and differential interference contrast microscopy, respectively. Images to the right are enlargements of the outlined regions in the left panel. Arrowheads point to SISOBIR1-GFP-labeled vesicle-like structures (second row) and germinating cysts (bottom row). Bars in the left and right panels represent 25 and $10 \mu \mathrm{m}$, respectively. styryl dye FM4-64 (Fig. 4A; Supplementary Fig. S4A), consistent with findings by Liebrand et al. (2013). However, in addition to plasma membrane, SISOBIR1-like-GFP also accumulated on some internal structures (Fig. 4A), indicative of localization to multiple membrane compartments or vesicles. Interestingly, when we challenged tobacco leaves expressing SISOBIR1GFP with $P$. parasitica, we observed increasing amounts of internal puncta labeled with SISOBIR1-GFP in a substantial population of cells (Fig. 4B). As germinating cysts are often found adjacent to these cells (Fig. 4B), we suggest that the accumulation of SISOBIR1-GFP internal puncta may correlate with $P$. parasitica infection.

To test whether the perception of PAMPs from Phytophthora spp. cause similar effects, we coexpressed SISOBIR1-GFP with various PAMPs on leaves of $N$. benthamiana. Interestingly, we found that coexpression with the $P$. parasitica elicitin ParA1 dramatically relocalized SISOBIR1-GFP from plasma membrane to multiple internal puncta (Fig. 5A). Further staining with FM4-64 confirmed the intactness of the plasma membrane and internalization of the fluorescent dye after ParA1 treatment. These results suggest that the $P$. parasitica elicitin ParA1 is sufficient to trigger SISOBIR1 internalization. Given that, in nature, ParA1 is secreted from $P$. parasitica to the apoplastic plant-pathogen interface, we next tested whether the ParA1induced SISOBIR1 internalization requires secretion of ParA1 to extracellular space. We found that SISOBIR1-GFP remains on the plasma membrane when it is coexpressed with ParA1$\Delta \mathrm{SP}$, a ParA1 variant lacking the $\mathrm{N}$-terminal signal peptide (Fig. 5A). Thus, ParA1 is likely secreted to the apoplastic space and perceived by the plant cell at the cell surface and, then, causes SISOBIR1 internalization.

To directly address whether treatment of ParA1 triggers SISOBIR1 internalization, we set up a simple system by which we expressed SISOBIR1-GFP in N. benthamiana protoplasts and treated the cells with purified recombinant ParA1 protein. To avoid observing SISOBIR1-GFP accumulation on transport vesicles or compartments along the secretory pathways, we incubated the protoplasts with $50 \mu \mathrm{M}$ cycloheximide (CHX) to block protein synthesis $30 \mathrm{~min}$ before and during ParA1 addition. When compared with the control, SISOBIR1-GFP, indeed, trafficked from the plasma membrane to highly mobile internal structures upon ParA1 treatment (Fig. 5B). Quantification results further indicated that the number of these internal structures in ParA1-treated protoplasts was significantly higher than that of buffer-treated, control protoplasts (Fig. 5C). We next tested the extent to which treatment of latrunculin B (LatB), a drug that blocks endocytosis by disrupting the assembly of actin cytoskeleton, could block the endocytosis of SOBIR1. Addition of LatB effectively impaired ParA1-induced S1SOBIR1-GFP internalization (Fig. 6A), as the number of vesicle-like structures formed in ParA1-treated protoplasts in the presence of LatB was significantly reduced to a level similar to a mock control (Fig. 6B).

To confirm that the punctate structures observed are endocytic vesicles, we coexpressed SISOBIR1-GFP with the early/late endosome marker AtARA6-mRFP (monomeric red fluorescence protein) and the early endosome marker mRFPAtARA7 (Lu et al. 2012). As shown in Figure 6C, AtARA6$\operatorname{mRFP}(70.8 \% \pm 10.9 \%)$ and mRFP-AtARA7 $(89.9 \% \pm 12.4 \%)$ largely colocalized with ParA1-induced SISOBIR1-GFP vesicle, supporting the idea that these structures are, indeed, endosomal compartments. Taken together, we conclude that perception of $P$. parasitica elicitin ParA1 at the plant cell surface triggers the endocytosis of SISOBIR1 from plasma membrane to various endosomal compartments in the cell.

Interestingly, we found that flg22 treatment did not trigger the endocytosis of SISOBIR1-GFP, although the same treatment 
relocalized the well-studied RLK FLS2 from the plasma membrane to punctate structures in the cytoplasm (Supplementary Fig. S5A). Similarly, treatment with CBEL in an agroinfiltration experiment failed to cause SISOBIR1-GFP internalization. Thus, our data clearly showed that SISOBIR1 responds specifically to ParA1 and, perhaps, other PAMPs but not all PAMPs. As SISOBIR1 is a RLK, we further asked whether the kinase domain of SISOBIR1 is essential for its internalization triggered by ParA1. Similar to SISOBIR1-GFP, the kinase-defective mutant SISOBIR1 ${ }^{\mathrm{D} 473 \mathrm{~N}}-\mathrm{GFP}$ (Liebrand et al. 2013) localized mainly to the plasma membrane, although the signal was much weaker (Supplementary Fig. S6). Treatment with ParA1 resulted in the formation of a very small number of SISOBIR $1^{\mathrm{D} 473 \mathrm{~N}}-\mathrm{GFP}-$ labeled puncta nearby the plasma membrane. Thus, the kinase activity is very likely required for ParA1-triggered endocytosis of SISOBIR1-GFP.

\section{NbSOBIR1 and NbSERK3/BAK1 are required}

\section{for ParA1-mediated cell death.}

The observation of ParA1 triggering SISOBIR1 endocytosis suggests that SOBIRl homologs are involved in elicitin perception in solanaceous plants. Hence, we silenced the expression of NbSOBIRl by TRV to determine whether it affects ParA1mediated cell death. We confirmed the silencing of NbSOBIRI by quantitative reverse transcription (qRT)-PCR at 3 weeks after virus inoculation (Supplementary Fig. S7A) and, then, expressed ParA1 in N. benthamiana leaves by agroinfiltration. Three days after agroinfiltration, necrosis appeared on control $N$. benthamiana leaves with the TRV empty vector (Fig. 7A, TRV). ParA1 treatment also induced $\mathrm{H}_{2} \mathrm{O}_{2}$ production and callose deposition (Fig. 7A, TRV). In contrast, the ParA1-induced necrosis, $\mathrm{H}_{2} \mathrm{O}_{2}$ production, and callose deposition were significantly compromised in NbSOBIRl-silenced leaves (Fig. 7A, TRV-NbSOBIR1). To know whether these effects were, indeed, caused by NbSOBIRI silencing, we coexpressed ParA1 with NbSOBIR1-GFP in the silenced tobacco plants. Moreover, P19 of Tomato bush stunt virus was coexpressed to attenuate the effect of TRV-mediated gene silencing. In contrast to coexpression of GFP as a control, coexpression of NbSOBIR 1 and $\mathrm{P} 19$ rescued ParA1-induced necrosis, $\mathrm{H}_{2} \mathrm{O}_{2}$ production, and callose deposition on NbSOBIRI-silenced tobacco leaves (Fig. 7B to E). Similarly, coexpression of SlSOBIRl-GFP, individually or in combination with SlSOBIRl-like-GFP, rescued the effects caused by ParA1 on NbSOBIRl-silenced tobacco leaves (Fig. 7B to E). However, coexpression with SISOBIRIlike-GFP only recovered callose deposition but not ParA1induced necrosis and $\mathrm{H}_{2} \mathrm{O}_{2}$ accumulation (Fig. 7B to E). In A. thaliana, overexpression of SOBIRl is known to cause cell death (Gao et al. 2009). To exclude the possibility that the necrosis symptom observed in the complementation experiment
A
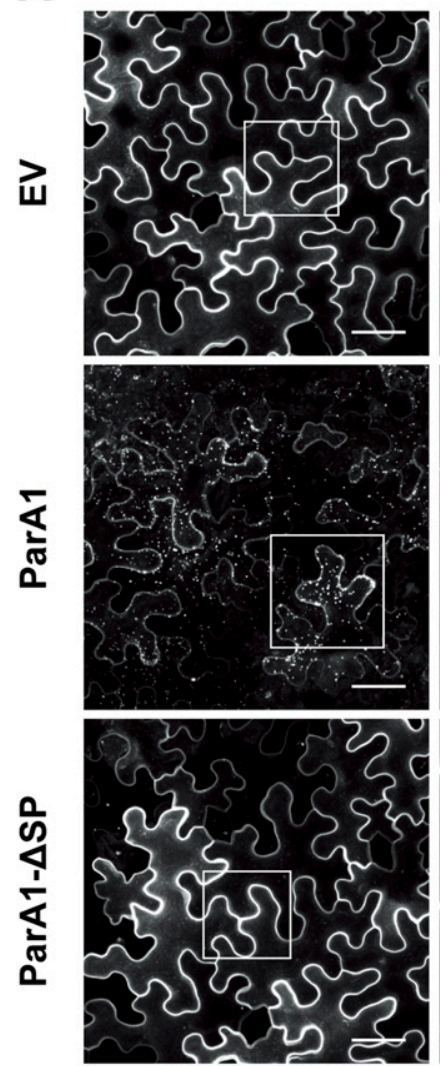

Zoom in
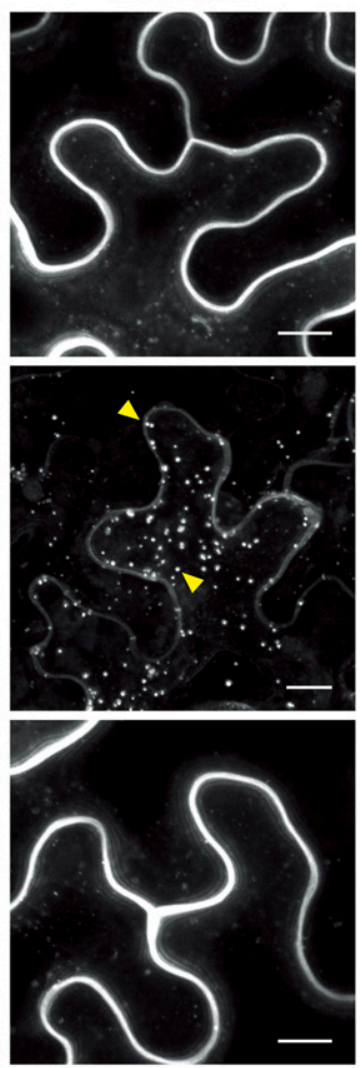

B

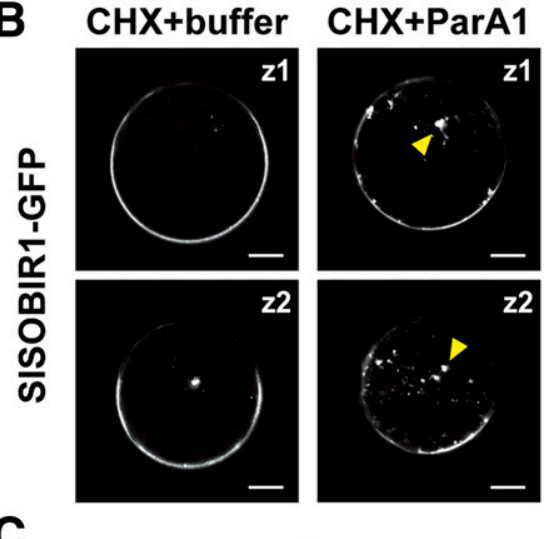

C

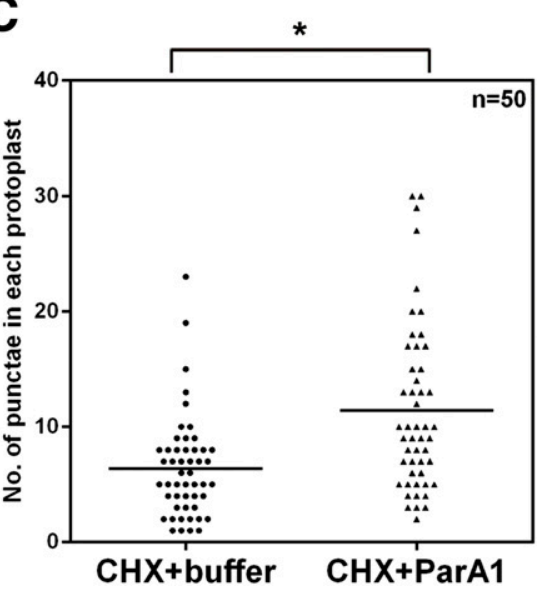

Fig. 5. SISOBIR1-GFP moved to vesicle-like structures in response to ParA1 treatment. A, Subcellular localization of SISOBIR1-GFP coexpressed with ParA1 or ParA1- $\Delta$ SP on Nicotiana benthamiana leaves. Agrobacterium tumefaciens harboring ParA1, ParA1- $\Delta$ SP, or an empty vector (EV) expression construct was coinfiltrated with that carrying SISOBIR1-GFP expression construct, and confocal images were captured at $23 \mathrm{~h}$ post-agroinfiltration. Images to the right are enlargements of the outlined regions in the left panel. Arrowheads indicate SISOBIR1-GFP-labeled vesicle-like structures. Bars in the left and right panels represent 25 and $10 \mu \mathrm{m}$, respectively. B, Confocal images of SISOBIR1-GFP in tobacco protoplasts in the presence of ParA1. After transformation with the SISOBIR1-GFP expression construct, tobacco protoplasts were treated with $50 \mu \mathrm{M}$ cycloheximide (CHX) for 30 min, and then, $300 \mu \mathrm{M}$ ParA1 recombinant protein (or buffer as a control) for another $30 \mathrm{~min}$. Arrowheads point to SISOBIR1-GFP-labeled vesicle-like structures. Images in the upper (Z1) and lower panels (Z2) were captured with different $z$-stacks. Bar $=10 \mu \mathrm{m}$. C, The number of SISOBIR1-GFP-labeled vesicle-like structures in tobacco protoplasts. Values are the numbers of vesicle-like structures in each protoplast $(n=50)$ from one of the three biological repeats, with the mean marked by a horizontal line. The asterisk (*) indicates $P<0.05$ by Student $t$ test. 
was caused by overexpression of SISOBIRl and SlSOBIRl-like, we expressed either of these two genes in N. benthamiana. By $72 \mathrm{~h}$ post-agroinfiltration, no symptom of necrosis developed on the leaves expressing SISOBIRl or SISOBIRl-like nor were $\mathrm{H}_{2} \mathrm{O}_{2}$ accumulation and callose deposition detectable, which is similar to results obtained with the control leaves expressing
GFP (Supplementary Fig. S8). In contrast, expression of ParAl caused necrosis, $\mathrm{H}_{2} \mathrm{O}_{2}$ accumulation, and callose deposition, as seen in the ParAl-expressing plants infected with the TRV empty vector (Fig. 7A). To test if the kinase activity of SISOBIR1 is essential for plant response to ParA1, we coexpressed ParA1 with kinase-defective mutant, SISOBIR1 $1^{\text {D473N }}$ or SISOBIR1-like ${ }^{\text {D486N }}$
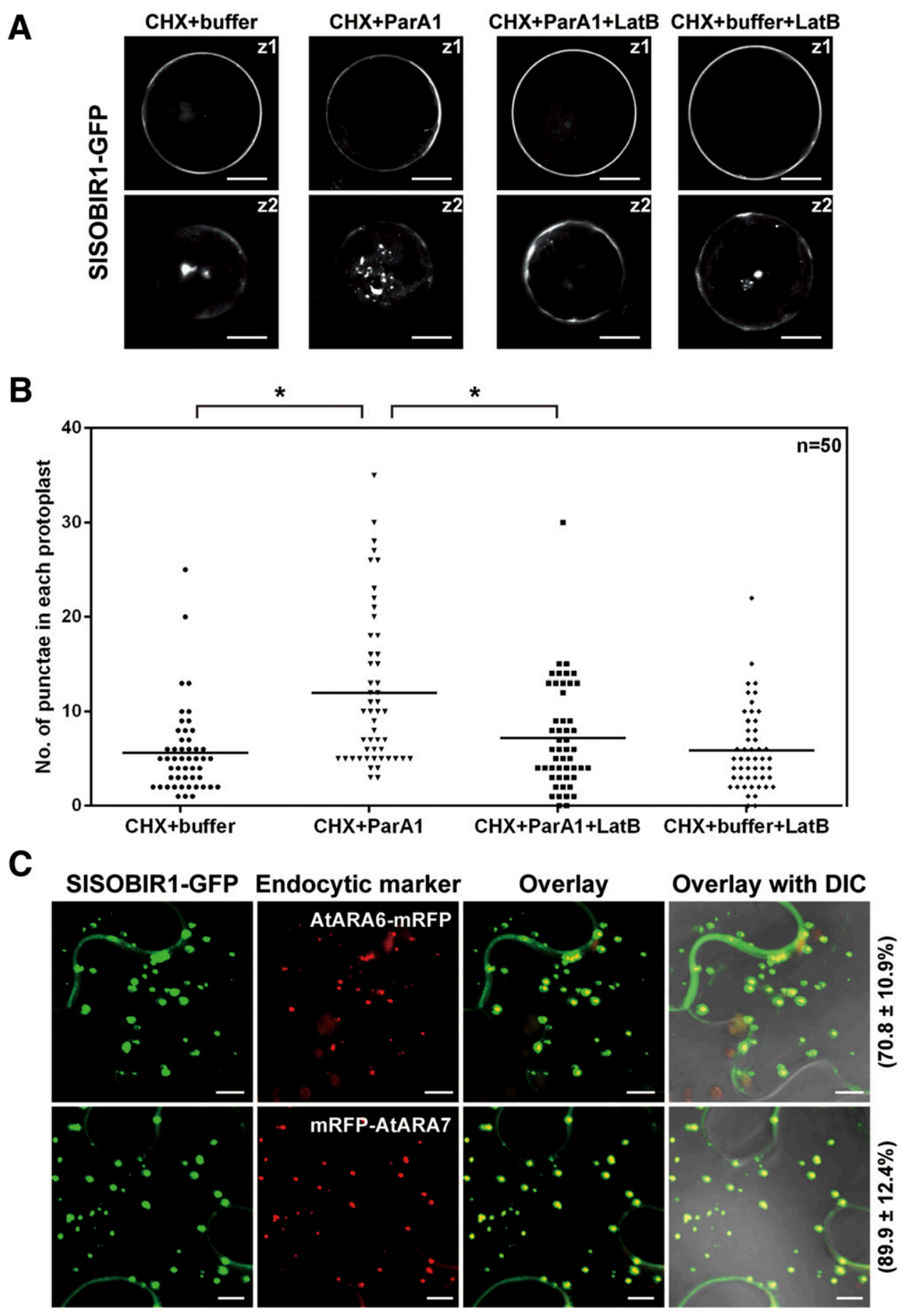

Fig. 6. Endocytosis of SISOBIR1-GFP in response to ParA1 treatment. A, Latrunculin B (LatB) impaired the movement of SISOBIR1-GFP in response to ParA1 treatment. Nicotiana benthamiana protoplasts expressing SISOBIR1-GFP were treated with $50 \mu \mathrm{M}$ cycloheximide (CHX) for $30 \mathrm{~min}$, and then, $300 \mu \mathrm{M}$ ParA1 recombinant proteins along with $20 \mathrm{nM}$ LatB (or buffer as a control) for another $30 \mathrm{~min}$, followed by capture of the confocal images with different $z$-stacks (Z1 and Z2). Bar $=10 \mu \mathrm{m}$. B, LatB reduced the number of ParA1-induced, SISOBIR1-GFP-labeled vesicle-like structure in the cytoplasm. Values are the numbers of vesicle-like structures in each protoplast $(n=50)$ from one of the three biological repeats, with the mean marked by a horizontal line. Asterisks (*) indicate $P<0.05$ by Student $t$ test. C, SISOBIR1-GFP colocalized with endocytic markers in Nicotiana benthamiana leaves in response to ParA1 treatment. At $23 \mathrm{~h}$ post-agroinfiltration for coexpression of SISOBIR1-GFP, ParA1, and the marker (AtARA6-mRFP or mRFP-AtARA7), images were captured under a confocal microscope. Values to the right of the figure represent mean ( \pm standard deviation) of the percentage of vesicles colabeled by SISOBIR1-GFP and the marker to those labeled only by SISOBIR1-GFP from three biological repeats. Bar $=10 \mu \mathrm{m}$. 
(Liebrand et al. 2013), and found neither of them rescued plant response to ParA1 (Fig. 7). Therefore, solanaceous SOBIRI homologs are involved in ParA1-induced necrosis and the kinase activity is essential for the response. It has been shown that NbSERK3/BAK1 regulates immune responses triggered by INF1 (Chaparro-Garcia et al. 2011). To test if NbSERK3/BAK1 is also required for ParA1-induced responses, we performed an experiment to silence the expression of $N b S E R K 3 A$ and $N b S E R K 3 B$ simultaneously by using a silencing construct that contains a conserved region of both genes. ParA1-induced necrosis was compromised in $N$. benthamiana leaves with NbSERK3/BAK1silencing, as evaluated by the symptoms and necrosis index (Supplementary Fig. S9A and B, respectively). Therefore, the immune responses mediated by oomycete elicitin in solanaceous plants appear to require both SERK3/BAK1 and SOBIR1/EVR homologs.

\section{DISCUSSION}

In this article, we demonstrate that SISOBIRl and its close homolog SlSOBIR1-like are involved in plant basal immunity to $P$. parasitica infection as well as plant responses triggered by elicitins. SOBIRI of A. thaliana was originally identified as a suppressor of $B I R 1$ mutation and its overexpression led to enhanced plant resistance to Pseudomonas syringae pv. tomato DC3000 (Gao et al. 2009). In contrast to A. thaliana, tomato contains two genes homologous to AtSOBIRl (i.e., SISOBIR1 and SlSOBIRl-like), as do other plants of family Solanaceae, such as potato and $N$. benthamiana. When either of these two genes was silenced, plants became more susceptible to pathogen infection, as revealed by enhanced disease severity and pathogen biomass present in the inoculated plants. Notably, with both genes silenced simultaneously, plants became even more susceptible to pathogen infection, which indicated the important role of both SISOBIRI and SlSOBIRl-like in plant basal defense. Hallmark events of PTI signaling encompass an enhancement of callose deposition and ROS production as well as induction of PTI marker genes (Boller and Felix 2009; Nguyen et al. 2010). Both callose deposition and ROS production were compromised in SISOBIR1 or/and SISOBIR1-like-silenced plants (Fig. 3). Moreover, the expression of Pti-5, WRKY28, and Gras2 was compromised in SISOBIRI-silenced plants. Thus, SISOBIRI and SISOBIRl-like play important roles in plant basal immunity toward $P$. parasitica, especially regarding the regulation of callose deposition and ROS production, but their roles in the control of defense gene expression are likely different.

In accordance with our results, the role of AtSOBIRI in basal defense response of $A$. thaliana was demonstrated in two recent independent studies (Zhang et al. 2013, 2014). SCLEROTINIA CULTURE FILTRATE ELICITOR1 (SCFE1), an elicitor identified in Sclerotinia sclerotiorum, induced typical MAMPtriggered immune responses that engaged a signaling pathway dependent on RECEPTOR-LIKE PROTEIN30, BAK1, and AtSOBIR1 (Zhang et al. 2013). Similar to mutants of RLP30 and BAK1, AtSOBIRl mutants were more susceptible to infection by necrotrophic fungal pathogens Sclerotinia sclerotiorum and Botrytis cinerea (Zhang et al. 2013). On the other hand, AtSOBIR1 and REPONSIVENESS TO BOTRYTIS POLYGALACTURONASE 1 (RBPG1), an LRR-RLP that acts as a receptor to recognize endopolygalacturonases (PG) of Botrytis cinerea, are involved in the formation of necrosis caused by PG (Zhang et al. 2014). When A. thaliana plants carrying a sobirl mutation were treated with PG, no symptom of necrosis developed and PG-induced resistance to Hyaloperonospora arabidopsidis was compromised (Zhang et al. 2014). It is thus obvious that SOBIRI homologs play essential roles in plant basal defense against a broad range of pathogens, including bacteria, fungi, and oomycetes. Furthermore, both SlSOBIRl and SlSOBIRl-like are required for HR induced by Cf-4 and Ve1, as well as for Cf-4- and Ve1-mediated tomato resistance to Cladosporium fulvum and Verticillium dahliae, respectively (Liebrand et al. 2013). In addition to their roles in plant innate immunity, SOBIRI/EVR is involved in floral abscission and functions downstream of NEVERSHED, which encodes an ADP-ribosylation factor GTPase-activating protein (Leslie et al. 2010). In this regard, SOBIRI/EVR is similar to BAK1, which is involved not only in plant development but also in plant immunity.

Upon pathogen infection, PRR interact with PAMPs, which is usually accompanied by the formation of receptor complexes and, then, receptor-mediated endocytosis (Geldner and Robatzek 2008; Leborgne-Castel et al. 2010; Monaghan and Zipfel 2012; Roux et al. 2011). When SISOBIR1-GFP and SISOBIR1like-GFP were expressed by agroinfiltration in N. benthamiana, SISOBIR1-GFP localized predominantly to the plasma membrane, similar to results reported by Liebrand et al. (2013). In contrast, SISOBIR1-like-GFP also localized in numerous cytoplasmic puncta in the $N$. benthamiana epidermal cells, likely due to constitutive endocytosis driven by endogenous signals, as reported for other RLK (Beck et al. 2012; Geldner et al. 2007). Intriguingly, SISOBIR1-GFP translocated from the plasma membrane to cytoplasmic puncta in response to $P$. parasitica infection. When various PAMPs were tested, we found that only ParA1 carrying an intact signal peptide could trigger internalization of SISOBIR1-GFP (Fig. 5A) and this process required an active kinase domain. Although the SISOBIR1-GFP-labeled cytoplasmic puncta may represent endocytic or secretory vesicles, our data clearly ruled out the latter case, because pretreatment with $\mathrm{CHX}$, a protein synthesis inhibitor, did not impair SISOBIR1-GFP internalization (Figs. 5 and 6). In yeast and mammals, actin cytoskeletons are known to play an important role during receptor-mediated endocytosis (Mooren et al. 2012). Similarly, an intact actin cytoskeleton is indispensable for endocytosis of plant RLK, such as the flagellin receptor FLS2 (Robatzek et al. 2006). To further characterize the phenomena of ParA1-induced SISOBIR1-GFP internalization, we treated tobacco protoplasts with the actin polymerization inhibitor (Spector et al. 1989) LatB, which has been shown to impair the internalization of FLS2 induced by flg22 (Robatzek et al. 2006). When tobacco protoplasts were treated with ParA1 and LatB, the number of SISOBIR1-GFPlabeled puncta was significantly reduced compared with the level of the control experiment treated only with ParA1 (Fig. 6). We also found that SISOBIR1-GFP colocalized with AtARA6 or AtARA7. In A. thaliana, both ARA6 and ARA7 play important roles in endocytic trafficking, with ARA6 mainly in late endosomes and ARA7 at both early and late endosomes (Ebine et al. 2011; Ueda et al. 2001). Thus, our findings indicate that ParA1 treatment triggers endocytosis of SISOBIR1-GFP, which traffics through ARA6- and ARA7-positive endosomal compartments in the cytoplasm. The fact that neither marker exhibits perfect colocalization with SISOBIR1-GFP suggests that, once being endocytosed, SISOBIR1-GFP is sorted in and out by multiple trafficking pathways among the complex endosomal compartments (Mooren et al. 2012). Further analyses are required to elucidate how exactly these endosomal trafficking pathways contribute to either recycling, turnover, or both of SISOBIR1-GFP and how the kinase activity of SISOBIR1 coordinates its interaction with other proteins upon PAMP perception.

Elicitins can induce necrosis in tobacco plants and some radish and turnip cultivars (Kamoun et al. 1993b). NbLRK1, a lectin-like receptor kinase, is known to interact with INF1 and mediate INF1-induced cell death in $N$. benthamiana (Kanzaki et al. 2008). 
Moreover, NbSERK3/BAK1-silencing abrogated HR induced by INF1 (Chaparro-Garcia et al. 2011). In our study, ParA1-induced necrosis on $N$. benthamiana leaves was compromised when the expression of NbSOBIRl was downregulated (Fig. 7), similar to the effects caused by silencing of NbSERK3/BAKI (including both $N b S E R K 3 A$ and $N b S E R K 3 B$ ). The importance of $S O B I R 1 / E V R$ homologs in plant response to elicitins were further verified by complementation experiments showing that both NbSOBIRI and SlSOBIRl but not SlSOBIRl-like could revert ParA1-indced responses in the silenced plants and, most importantly, the kinase activity is essential for complementation. Therefore, in addition to NbSERK3/BAK1,
A

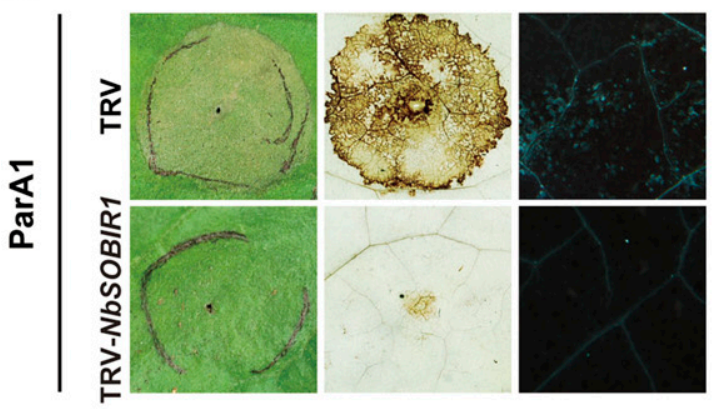

B

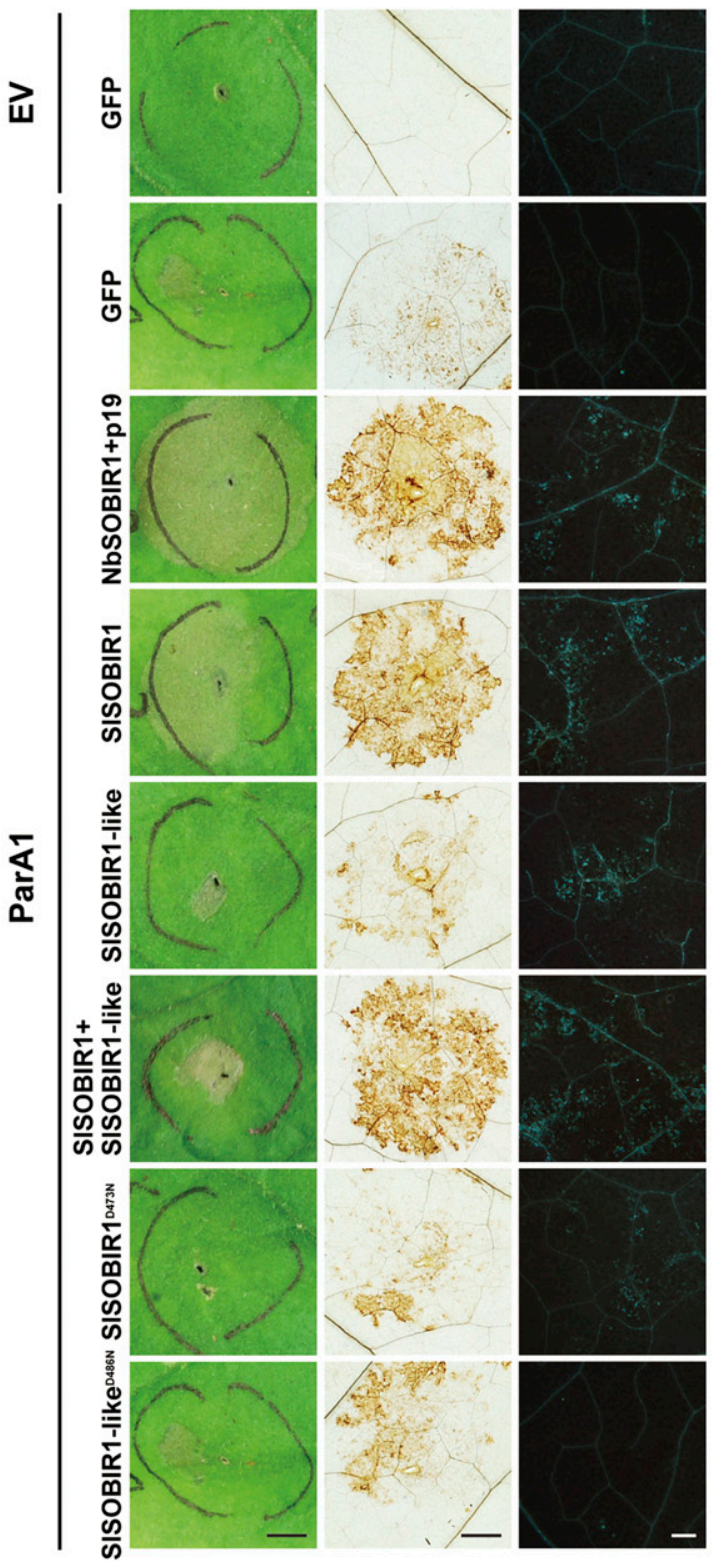

C

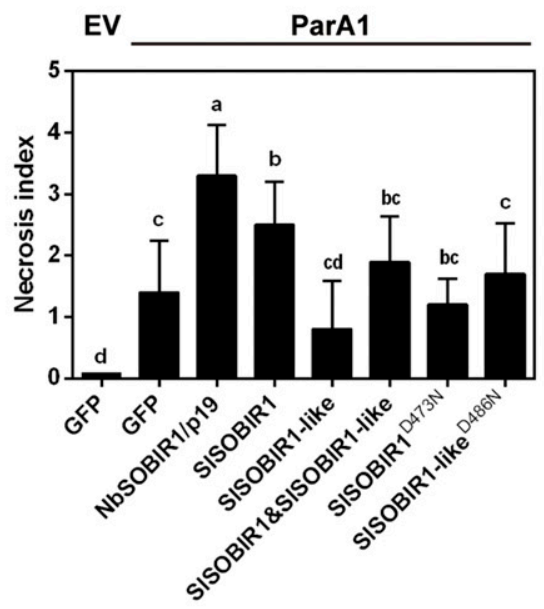

D

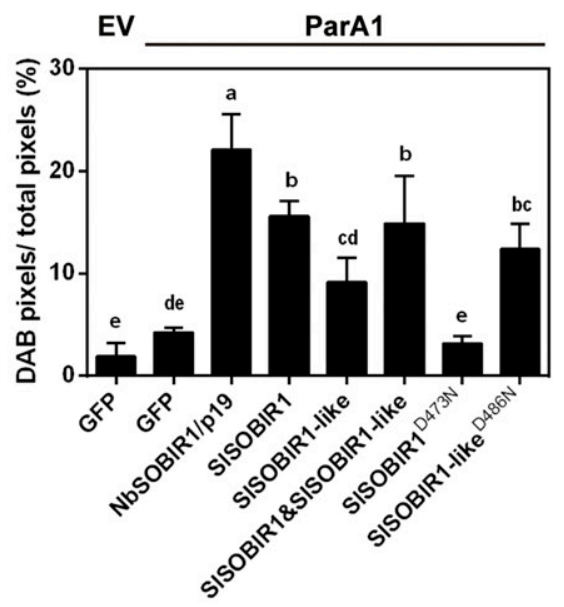

$\mathbf{E}$

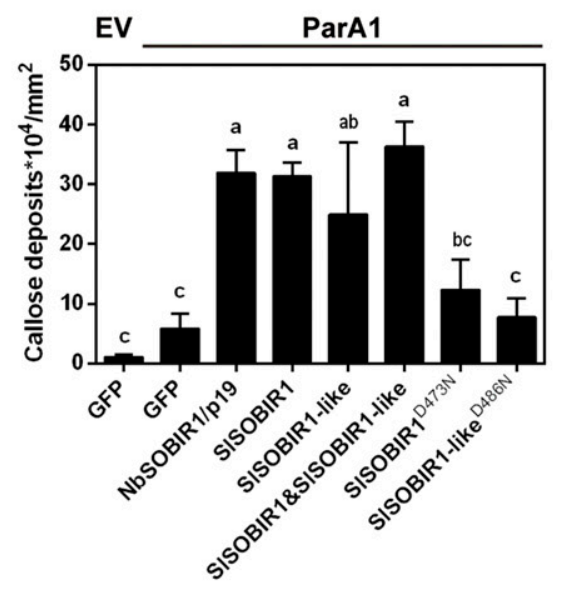


$N b S O B I R 1$ is required for ParA1-induced plant responses, and the function of NbSOBIRI is well conserved in SISOBIRl but not SlSOBIRl-like, despite of the high identity between these two proteins.

The fact that only ParA1 with an intact signal peptide can trigger endocytosis of SOBIR1-GFP indicated that the whole event involves an interaction between ParA1 and its receptor from the cell surface. Currently, no elicitin receptor was identified, although high-affinity binding sites specific to cryptogein, an elicitin from Phytophthora cryptogea, have been reported (Wendehenne et al. 1995) and treatment with cryptogein rapidly stimulated both FM4-64 internalization and clathrin-mediated endocytosis in tobacco bright yellow-2 (BY-2) cells (Leborgne-Castel et al. 2008). It is likely that, following perception of ParA1, the ParA1 receptor interacts with other proteins in the plasma membrane, such as SISOBIRI, thereby resulting in the formation and subsequent endocytosis of receptor complexes for downstream signaling. In A. thaliana, AtSOBIRl was shown to interact with RBPG1 (Zhang et al. 2014). As well, tomato SlSOBIRl/EVR homologs can interact with several RLP, including Cf proteins, Ve1, and LeEix2 (Liebrand et al. 2013). Accordingly, it has been proposed that SOBIR1/EVR homologs may function as a regulatory LRR-RLK that is involved in the formation of a plethora of plasma membrane-associated receptor complexes (Liebrand et al. 2014). Identification of proteins that interact with NbSOBIRl may help to identify other components of the ParA1-induced receptor complexes and to uncover the early events that occur after recognition of elicitins.

\section{MATERIALS AND METHODS}

\section{Growth of $\boldsymbol{P}$. parasitica and plant materials.}

$P$. parasitica (isolate 94069 ) was routinely grown on $5 \% \mathrm{~V} 8$ juice agar (5\% Campbell's V8 juice, $0.02 \% \mathrm{CaCO}_{3}$, and $2 \%$ agar) at $25^{\circ} \mathrm{C}$ in the dark. Tomato plants (S. lycopersicum cv. Summer Sweet) were grown at $22^{\circ} \mathrm{C}$ under a 16 -h light and 8-h dark cycle, and $N$. benthamiana was grown at $25^{\circ} \mathrm{C}$ under a 12-h light and dark cycle, both in a mixture of peat moss, perlite, and vermiculite.

\section{Cloning and sequence analysis of SOBIR1/EVR homologs.}

Total RNA samples were prepared from tomato and tobacco tissues by using the Plant Total RNA extraction kit (ViogeneBiotek, Taipei, Taiwan). The Turbo-DNA free kit (Ambion, Huntingdon, U.K.) was used to remove residual DNA in RNA samples. First-strand cDNA was synthesized by use of SuperScript III reverse transcription (Life Technologies-Invitrogen, Carlsbad, CA, U.S.A.) and was used for amplification of SlSOBIR1, SlSOBIRl-like, and NbSOBIR1 with the primers listed in Supplementary Table S1. The amplified DNA fragments were cloned into pGEM-T Easy vector (Promega, Madison, WI, U.S.A.) for sequencing and further subcloning. Sequences have been deposited in GenBank [accession numbers KF268115 (SlSOBIR1), KF977196 (SlSOBIRl-like), and KF998581 $(\mathrm{NbSOBIRl)}$. Multiple sequence alignment involved use of ClustalX. A phylogenetic tree was generated by the neighborjoining algorithm, implemented in MEGA 5 with the default parameters. Nodal support of the tree was estimated by bootstrapping with 3,000 pseudoreplicate data sets.

\section{Inoculation of $P$. parasitica, scoring of disease severity, and quantification of pathogen biomass by qPCR.}

Zoospores of $P$. parasitica were prepared as described (Yan and Liou 2006). For inoculation, zoospore suspensions $\left(5 \times 10^{5}\right.$ zoospores $/ \mathrm{ml}$ ) were sprayed evenly on the aerial parts of tomato plants until run-off, and inoculated plants were kept in a moisture chamber to facilitate disease development. Disease severity was scored on a scale from 0 to 5 , according to symptoms developed on tomato plants: 0 , healthy, no water-soaking lesions; $1,<25 \%$ lesions; 2,25 to $50 \%$ lesions; 3,50 to $75 \%$ lesions; 4, 75 to $100 \%$ lesions; and 5, complete wilting. To quantify pathogen biomass by qPCR, genomic DNA samples were prepared from inoculated plants by using EasyPure genomic DNA spin kit (Bioman Scientific, New Taipei, Taiwan). qPCR involved use of StepOnePlus real-time PCR system (Applied Biosystems, Foster City, CA, U.S.A.) and Power SYBR green PCR master mix (Applied Biosystems), using primers targeting $P$. parasitica WS21 (CF891675) and tomato eIf5A-4 (NM_001247786)), respectively. The experiments were repeated three times. Raw data from WS21 were normalized with those from tomato eIf $5 A-4$ and are presented as fold change relative to plants infiltrated with the empty vector (TRV) at 24 hpi.

\section{Treatment with plant hormones.}

Four-week-old tomato plants were treated with $2 \mathrm{mM}$ SA (Sigma-Aldrich, St. Louis) or 1.25 mM MeJA (Sigma-Aldrich). For ET treatment, 4-week-old tomato plants were exposed to $10 \mathrm{ppm}$ ET gas in a 9.4-liter air-tight container for $24 \mathrm{~h}$ in the dark. Final concentration of the ET gas in the container was measured by gas chromatography at the end of each treatment, to confirm the treatment. Leaf samples were collected at the indicated times for gene expression analysis.

\section{qRT-PCR.}

Plant total RNA and cDNA were prepared as described in the previous section. qPCR involved use of StepOnePlus real-time PCR system and Power SYBR green PCR master mix with primers. The transcript of elf5A-4 was used as an internal control for analysis in tomato and EFl $\alpha$ (AF120093) in N. benthamiana.

Fig. 7. Silencing of NbSOBIR1 compromises ParA1-induced necrosis. A, ParA1-induced necrosis, reactive oxygen species accumulation, and callose deposition were compromised in NbSOBIR1-silenced Nicotiana benthamiana leaves. At 21 days after virus inoculation for Tobacco rattle virus (TRV)mediated gene silencing of $N b S O B I R 1$, ParA1 was expressed in systemic leaves by agroinfiltration. 3,3'-Diaminobenzidine (DAB) and aniline blue staining were performed at $48 \mathrm{~h}$, whereas images of necrosis were obtained at $72 \mathrm{~h}$ post-agroinfiltration. TRV is the empty vector serving as a control. Bars in the left and middle panels represent $5 \mathrm{~mm}$ and, in the right panel, $1 \mu \mathrm{m}$. B, NbSOBIR1 and SlSOBIR1 can rescue the effect caused by ParA1 on NbSOBIRI-silenced Nicotiana benthamiana leaves. At 21 days after virus inoculation for Tobacco rattle virus (TRV)-mediated gene silencing of NbSOBIR1, ParA1 (or the empty vector $[\mathrm{EV}]$ as a control) and the indicated proteins were coexpressed in systemic leaves by agroinfiltration. DAB and aniline blue staining were performed at $48 \mathrm{~h}$, whereas images of necrosis were obtained at $72 \mathrm{~h}$ post-agroinfiltration. Bars in the left and middle panels represent $5 \mathrm{~mm}$ and, in the right panel, $1 \mu \mathrm{m}$. $\mathbf{C}$, Necrosis index. ParA1-induced necrosis on $N$. benthamiana leaves were scored for necrosis severity as follows: 0 , no symptoms; 1 , yellowing at the infiltrated area; 2 , necrosis, $<50 \%$ of the infiltrated area; 3 , necrosis, $\geq 50 \%$ of the infiltrated area; 4 , necrosis, $100 \%$ of the infiltrated area. Values are mean ( \pm standard deviation [SD]) from three independent experiments. Different letters indicate significant difference among treatments by one-way analysis of variance (ANOVA) at $P<0.01$. D, Quantification of DAB staining. Values are mean $( \pm$ SD) from three independent experiments. Different letters indicate significant difference among treatments by one-way ANOVA at $P<0.01$. E, Quantification of aniline blue staining. Values are means ( \pm SD) from three independent experiments. Different letters indicate significant difference among treatments revealed by one-way ANOVA at $P<0.01$. 


\section{Virus-induced gene silencing.}

Virus-induced gene silencing was performed as described (Liu et al. 2002), with some modifications. Briefly, partial sequences of target genes were amplified by PCR with respective primers and were cloned into pTRV2 (pYL279) by Gateway cloning (Life Technologies-Invitrogen). Plasmids were then transformed into Agrobacterium tumefaciens GV3101. For virus inoculation, bacteria were grown in Luria-Bertani broth with rifampicin and kanamycin at $28^{\circ} \mathrm{C}$ for $18 \mathrm{~h}$. The culture was diluted 200x with induction medium (Luria-Bertani broth with $20 \mu \mathrm{M}$ acetosyringone and $50 \mathrm{ppm}$ kanamycin) and was incubated at $28^{\circ} \mathrm{C}$ for $16 \mathrm{~h}$. After centrifugation, bacteria were resuspended with MMA (10 mM MES, pH 5.6, $10 \mathrm{mM} \mathrm{MgCl} 2,200 \mu \mathrm{M}$ acetosyringone) and were adjusted to an optical density at $600 \mathrm{~nm}\left(\mathrm{OD}_{600}\right)=2$. Bacteria harboring TRV1 (pYL192) were mixed with an equal volume of bacteria harboring TRV2 and were infiltrated onto cotyledons of 7-day-old tomato seedlings or leaves of 18-day-old $N$. benthamiana seedlings by use of $1-\mathrm{ml}$ syringes.

\section{3,3'-Diaminobenzidine (DAB) staining.}

DAB staining was performed as described (Bindschedler et al. 2006). Tomato leaves were immersed in $\mathrm{DAB}-\mathrm{HCl}$ solution ( $1 \mathrm{mg}$ of DAB per milliliter, $0.05 \%$ [ $\mathrm{vol} / \mathrm{vol}$ ] Tween 20 , and $10 \mathrm{mM} \mathrm{Na}_{2} \mathrm{HPO}_{4}, \mathrm{pH} \mathrm{3.0)}$ for at least $8 \mathrm{~h}$ and were then decolorized in bleaching solution $(95 \%$ ethanol/acetic acid/glycerol [3:1:1]) for $10 \mathrm{~min}$. Leaves were fixed and preserved in $95 \%$ ethanol. Images were captured by use of a Nikon digital camera D50. Intensity of DAB staining was quantified using Image $J$ and is presented as the ratio of $\mathrm{DAB}$ dark-brown to total pixels. For each treatment, ten leaves from five plants were analyzed, with all the experiments repeated three times.

\section{Staining and quantification for callose deposition.}

Callose staining was performed as described (Luna et al. 2011), with some modifications. Tomato leaf disks were incubated in $95 \%$ ethanol at $37^{\circ} \mathrm{C}$ until transparent, were then stained with $0.1 \%$ aniline blue (Sigma-Aldrich) in $150 \mathrm{mM}$ $\mathrm{K}_{2} \mathrm{HPO}_{4}$ (pH 9.5), and were incubated in the dark overnight. Callose deposition at the adaxial surface was examined by use of a Leica DM LB microscope (Buffalo Grove, IL, U.S.A.) equipped with filter cube A (BP 340 to $380 \mathrm{~nm}, \mathrm{LP} 425 \mathrm{~nm}$ ) and Canon digital camera EOS 550D. Callose deposition was quantified by the number of depositions per square millimeter microscopic field by use of ImageJ. For each treatment, ten leaf discs and three images for each leaf disc were analyzed, with all the experiments repeated three times.

\section{Transient protein expression by agroinfiltration.}

Coding sequences of SISOBIRI and SlSOBIRI-like were subcloned into pK7FWG2 by use of the pENTR/D-TOPO cloning kit and Gateway LR Clonase II enzyme mix (Life Technologies-Invitrogen). Kinase-defective mutants of SlSOBIRI and SISOBIRI-like were generated according to Liebrand et al. (2013). Plasmid constructs for AtARA6-mRFP and mRFP-AtARA7 were gifts from S. Robatzek and K. Schumacher. Coding sequences of AtARA6-mRFP and mRFP-AtARA7 were subcloned into pK7WG2 by use of the pENTR/D-TOPO cloning kit and Gateway LR Clonase II enzyme mix. The young expanding leaves of four-week-old $N$. benthamiana were used for transient protein expression. To express protein, Agrobacterium tumefaciens $\mathrm{C} 58 \mathrm{C} 1$ strains carrying the expression constructs or Agrobacterium tumefaciens GV3101 strains carrying pK7FWG2::FLS2 (Schwessinger et al. 2011) were prepared as described in the previous section and were adjusted to $\mathrm{OD}_{600}=0.6$ with MMA. Staining of the plasma membrane by $51 \mathrm{~g}$ of FM4-64 per milliliter (Life TechnologiesInvitrogen) was performed as described (Bolte et al. 2004). Fluorescence signals from GFP and mRFP were visualized by use of a Zeiss LSM 510 Meta confocal microscope (GFP: excitation $488 \mathrm{~nm}$ and emission 500 to $550 \mathrm{~nm}$; mRFP: excitation $543 \mathrm{~nm}$ and emission 565 to $615 \mathrm{~nm}$ ). Colocalization of fluorescent proteins was evaluated by use of the MetaMorph NX microscopy automation and Image analysis software (Molecular Devices, Sunnyvale, CA, U.S.A.). For each treatment, 50 photographs from five different leaf discs were used for statistical analysis, with all the experiments repeated three times.

\section{Transient protein expression}

in $N$. benthamiana protoplasts.

Protoplasts of $N$. benthamiana were prepared as described by $\mathrm{Wu}$ et al. (2011) with some modifications. Leaves of 6-weekold tobacco were cut in pieces that were incubated in the protoplast enzyme digestion buffer (per milliliter: $1 \mathrm{mg}$ of bovine serum albumin, $12 \mathrm{mg}$ of cellulose [Yakult, Tokyo], and $0.6 \mathrm{mg}$ of macerozyme [Yakult]) for $16 \mathrm{~h}$ at room temperature. The lysate was then filtered through a 600-mesh cloth into sterile glass tubes and was centrifuged at $300 \mathrm{rpm}$ (Eppendorf 5810) for $5 \mathrm{~min}$, followed by resuspension of pellets in mannitol buffer (0.55 M mannitol, 0.1\% MES, pH 5.7). After addition of an equal volume of sucrose solution $(0.55 \mathrm{M})$, the protoplasts were harvested by centrifugation at $300 \mathrm{rpm}$ for $5 \mathrm{~min}$ and were then resuspended with MMg buffer $(0.55 \mathrm{M}$ mannitol, $15 \mathrm{mM}$ $\mathrm{MgCl}_{2} \cdot \mathrm{H}_{2} \mathrm{O}$, and $4 \mathrm{mM}$ MES, pH 5.7) in a clean glass tube to a final concentration of $10^{6}$ protoplasts $/ \mathrm{ml}$. For polyethylene glycerol (PEG)-mediated transformation, the protoplast suspension was mixed with $15 \mathrm{lg}$ of plasmid DNA per microliter in a PEG solution $(0.4 \mathrm{~g}$ of PEG-4000 per milliliter [SigmaAldrich], $0.55 \mathrm{M}$ mannitol, and $0.1 \mathrm{M} \mathrm{CaCl}_{2}$ ) and was incubated at room temperature for $45 \mathrm{~min}$. Afterward, the protoplasts were rinsed twice with W5 buffer $(154 \mathrm{mM} \mathrm{NaCl}$, $125 \mathrm{mM} \mathrm{CaCl}_{2} \cdot \mathrm{H}_{2} \mathrm{O}, 5 \mathrm{mM} \mathrm{KCl}$, and $2 \mathrm{mM}$ MES, pH 5.7) to get rid of PEG and were then incubated at room temperature for $8 \mathrm{~h}$ under light. Of the expression constructs, p35S-SISOBIR1GFP was obtained by subcloning the coding sequence of SISOBIR1 into p35S-MCS-GFP. To block protein synthesis and endocytosis, the protoplasts were treated with $50 \mu \mathrm{M}$ CHX (Sigma-Aldrich) and $20 \mu \mathrm{M}$ latrunculin B (Sigma-Aldrich), respectively, for $30 \mathrm{~min}$ as described by Gibbon et al. (1999). Fluorescence signals were visualized by use of a Zeiss LSM 510 Meta confocal microscope (GFP: excitation $488 \mathrm{~nm}$ and emission 500 to $550 \mathrm{~nm}$ ), and the number of fluorescent protein-labeled vesicles per square millimeter microscopic field was quantified for 50 protoplasts, with all the experiments repeated three times.

\section{Transient expression of CBEL and ParA1.}

CBEL, ParAl, and ParAl devoid of the signal peptide (ParAl- $\triangle S P$ ) were amplified by using cDNA of $P$. parasitica and primers. The cDNA fragments were cloned into $\mathrm{pBI}-\mathrm{V}$ MCS (courtesy of Y. C. Chang, National Taiwan University), a modified pBI121 binary vector (Chen et al. 2003) with the multiple cloning sites from pBluescript SK+ replacing the $\beta$-glucuronidase sequence, under the control of the $35 \mathrm{~S}$ promoter. For transient expression, Agrobacterium tumefaciens C58C1 strains harboring the expression plasmids were grown as described previously and were adjusted to a final concentration of $\mathrm{OD}_{600}=0.1$ with MMA. The severity of cell death induced by ParA1 on $N$. benthamiana leaves was scored at $48 \mathrm{~h}$ post-agroinfiltration as follows: 0 , no symptoms; 1 , yellowing at the infiltrated area; 2 , necrosis, $<50 \%$ of the infiltrated area; 3 , necrosis, $\geq 50 \%$ of the infiltrated area; 4 , necrosis, $100 \%$ of the infiltrated area. 


\section{Expression and purification of ParA1 recombinant protein.}

The coding sequence of ParAl devoid of the signal peptide was subcloned into the expression vector pET20b (+), and the recombinant plasmid was transformed into Escherichia coli $\mathrm{C} 43$ (DE3). After growth of the bacteria at $37^{\circ} \mathrm{C}$ to reach $\mathrm{OD}_{600}=1$, the expression of recombinant protein was induced by the addition of $0.4 \mathrm{mM}$ isopropyl- $\beta$-D-thiogalactoside, accompanied by further incubation at $30^{\circ} \mathrm{C}$ for $24 \mathrm{~h}$. The recombinant proteins were purified by use of Ni-NTA agarose (Qiagen, Valencia, CA, U.S.A.) as described by Hofzumahaus and Schallmey (2013).

\section{Treatment with flg22.}

Flg22 was synthesized by Genomics (New Taipei, Taiwan). After resuspension in $0.1 \mathrm{M}$ MES to a final concentration of $1 \mu \mathrm{M}$, flg22 was infiltrated into $N$. benthamiana leaves by use of $1-\mathrm{ml}$ syringes.

\section{Statistical analysis.}

Statistically significant differences were analyzed by Student $t$ test, one-way analysis of variance (ANOVA) or Wilcoxon rank-sum test. Significance was set at $P<0.05$ or $P<0.01$ and was determined by PASW Statistics 18 (SPSS Inc., Chicago).

\section{ACKNOWLEDGMENTS}

We thank C. P. Cheng (National Taiwan University) for technical assistance on the TRV-mediated gene silencing experiments, T. T. Wang (National Taiwan University) for the ethylene treatment experiments, C. Zipfel (The Sainsbury Laboratory, U.K.) for FLS2-GFP construct, and S. Robatzek (The Sainsbury Laboratory) and K. Schumacher (Centre for Organismal Studies, Heidelberg University, Germany) for endosome markers. We are grateful to have M.-J. Fang and J.-Y. Huang of the LiveCell Imaging Core Laboratory (IPMB, Academia Sinica) for advice on imaging. This work was supported by Ministry of Science and Technology, Taiwan (98-2313-B-002-035-MY3 and 102-2628-B-002-021-MY3).

\section{LITERATURE CITED}

Altenbach, D., and Robatzek, S. 2007. Pattern recognition receptors: From the cell surface to intracellular dynamics. Mol. Plant-Microbe Interact. 20:1031-1039.

Baldauf, S. L., Roger, A. J., Wenk-Siefert, I., and Doolittle, W. F. 2000. A kingdom-level phylogeny of eukaryotes based on combined protein data. Science 290:972-977.

Bar, M., and Avni, A. 2009. EHD2 inhibits ligand-induced endocytosis and signaling of the leucine-rich repeat receptor-like protein LeEix2. Plant J. 59:600-611.

Bar, M., and Avni, A. 2014. Endosomal trafficking and signaling in plant defense responses. Curr. Opin. Plant Biol. 22:86-92.

Beck, M., Zhou, J., Faulkner, C., MacLean, D., and Robatzek, S. 2012. Spatio-temporal cellular dynamics of the Arabidopsis flagellin receptor reveal activation status-dependent endosomal sorting. Plant Cell 24: 4205-4219.

Bindschedler, L. V., Dewdney, J., Blee, K. A., Stone, J. M., Asai, T., Plotnikov, J., Denoux, C., Hayes, T., Gerrish, C., Davies, D. R., Ausubel, F. M., and Bolwell, G. P. 2006. Peroxidase-dependent apoplastic oxidative burst in Arabidopsis required for pathogen resistance. Plant J. 47:851-863.

Boller, T., and Felix, G. 2009. A renaissance of elicitors: Perception of microbe-associated molecular patterns and danger signals by patternrecognition receptors. Annu. Rev. Plant Biol. 60:379-406.

Bolte, S., Talbot, C., Boutte, Y., Catrice, O., Read, N. D., and SatiatJeunemaitre, B. 2004. FM-dyes as experimental probes for dissecting vesicle trafficking in living plant cells. J. Microsc. 214:159-173.

Brunner, F., Rosahl, S., Lee, J., Rudd, J. J., Geiler, C., Kauppinen, S., Rasmussen, G., Scheel, D., and Nürnberger, T. 2002. Pep-13, a plant defense-inducing pathogen-associated pattern from Phytophthora transglutaminases. EMBO (Eur. Mol. Biol. Organ.) J. 21:6681-6688.

Chaparro-Garcia, A., Wilkinson, R. C., Gimenez-Ibanez, S., Findlay, K., Coffey, M. D., Zipfel, C., Rathjen, J. P., Kamoun, S., and Schornack, S. 2011. The receptor-like kinase SERK3/BAK1 is required for basal resistance against the late blight pathogen phytophthora infestans in Nicotiana benthamiana. PLoS ONE 6:e16608.

Chen, P. Y., Wang, C. K., Soong, S. C., and To, K. Y. 2003. Complete sequence of the binary vector pBI121 and its application in cloning T-DNA insertion from transgenic plants. Mol. Breed. 11:287-293.

Chinchilla, D., Zipfel, C., Robatzek, S., Kemmerling, B., Nürnberger, T. Jones, J. D., Felix, G., and Boller, T. 2007. A flagellin-induced complex of the receptor FLS2 and BAK1 initiates plant defence. Nature 448: 497-500.

Chinchilla, D., Shan, L., He, P., de Vries, S., and Kemmerling, B. 2009. One for all: The receptor-associated kinase BAK1. Trends Plant Sci. 14: 535-541.

Dodds, P. N., and Rathjen, J. P. 2010. Plant immunity: Towards an integrated view of plant-pathogen interactions. Nat. Rev. Genet. 11: 539-548.

Ebine, K., Fujimoto, M., Okatani, Y., Nishiyama, T., Goh, T., Ito, E., Dainobu, T., Nishitani, A., Uemura, T., Sato, M. H., ThordalChristensen, H., Tsutsumi, N., Nakano, A., and Ueda, T. 2011. A membrane trafficking pathway regulated by the plant-specific RAB GTPase ARA6. Nat. Cell Biol. 13:853-859.

Erwin, D. C., and Ribeiro, O. K. 1996. Phytophthora diseases worldwide. American Phytopathological Society, St. Paul, MN, U.S.A.

Gao, M., Wang, X., Wang, D., Xu, F., Ding, X., Zhang, Z., Bi, D., Cheng, Y. T., Chen, S., Li, X., and Zhang, Y. 2009. Regulation of cell death and innate immunity by two receptor-like kinases in Arabidopsis. Cell Host Microbe 6:34-44.

Gaulin, E., Dramé, N., Lafitte, C., Torto-Alalibo, T., Martinez, Y., AmelineTorregrosa, C., Khatib, M., Mazarguil, H., Villalba-Mateos, F., Kamoun, S. Mazars, C., Dumas, B., Bottin, A., Esquerré-Tugayé, M. T., and Rickauer, M. 2006. Cellulose binding domains of a Phytophthora cell wall protein are novel pathogen-associated molecular patterns. Plant Cell 18:1766-1777.

Geldner, N., and Robatzek, S. 2008. Plant receptors go endosomal: A moving view on signal transduction. Plant Physiol. 147:1565-1574.

Geldner, N., Hyman, D. L., Wang, X., Schumacher, K., and Chory, J. 2007. Endosomal signaling of plant steroid receptor kinase BRI1. Genes Dev. 21:1598-1602.

Gibbon, B. C., Kovar, D. R., and Staiger, C. J. 1999. Latrunculin B has different effects on pollen germination and tube growth. Plant Cell 11: 2349-2363.

Gómez-Gómez, L., and Boller, T. 2000. FLS2: An LRR receptor-like kinase involved in the perception of the bacterial elicitor flagellin in Arabidopsis. Mol. Cell 5:1003-1011.

He, K., Gou, X., Yuan, T., Lin, H., Asami, T., Yoshida, S., Russell, S. D., and Li, J. 2007. BAK1 and BKK1 regulate brassinosteroid-dependent growth and brassinosteroid-independent cell-death pathways. Curr. Biol 17:1109-1115.

Heese, A., Hann, D. R., Gimenez-Ibanez, S., Jones, A. M., He, K., Li, J., Schroeder, J. I., Peck, S. C., and Rathjen, J. P. 2007. The receptor-like kinase SERK3/BAK1 is a central regulator of innate immunity in plants. Proc. Natl. Acad. Sci. U.S.A. 104:12217-12222.

Hofzumahaus, S., and Schallmey, A. 2013. Escherichia coli-based expression system for the heterologous expression and purification of the elicitin $\beta$-cinnamomin from Phytophthora cinnamomi. Protein Expr. Purif. 90:117-123.

Jones, J. D., and Dangl, J. L. 2006. The plant immune system. Nature 444 : 323-329.

Kamoun, S., Klucher, K. M., Coffey, M. D., and Tyler, B. M. 1993a. A gene encoding a host-specific elicitor protein of Phytophthora parasitica. Mol. Plant-Microbe Interact. 6:573-581

Kamoun, S., Young, M., Glascock, C. B., and Tyler, B. M. 1993b. Extracellular protein elicitors from Phytophthora: Host-specificity and induction of resistance to bacterial and fungal phytopathogens. Mol. Plant-Microbe Interact. 6:15-25.

Kamoun, S., van West, P., de Jong, A. J., de Groot, K. E., Vleeshouwers, V. G., and Govers, F. 1997. A gene encoding a protein elicitor of Phytophthora infestans is down-regulated during infection of potato. Mol. Plant-Microbe Interact. 10:13-20.

Kamoun, S., Furzer, O., Jones, J. D., Judelson, H. S., Ali, G. S., Dalio, R. J., Roy, S. G., Schena, L., Zambounis, A., Panabières, F., Cahill, D., Ruocco, M., Figueiredo, A., Chen, X. R., Hulvey, J., Stam, R., Lamour, K., Gijzen, M., Tyler, B. M., Grünwald, N. J., Mukhtar, M. S., Tomé, D. F., Tör, M., Van Den Ackerveken, G., McDowell, J., Daayf, F., Fry, W. E., LindqvistKreuze, H., Meijer, H. J., Petre, B., Ristaino, J., Yoshida, K., Birch, P. R., and Govers, F. 2015. The top 10 oomycete pathogens in molecular plant pathology. Mol. Plant Pathol. 16:413-434.

Kanzaki, H., Saitoh, H., Takahashi, Y., Berberich, T., Ito, A., Kamoun, S., and Terauchi, R. 2008. NbLRK1, a lectin-like receptor kinase protein of 
Nicotiana benthamiana, interacts with Phytophthora infestans INF1 elicitin and mediates INF1-induced cell death. Planta 228:977-987.

Leborgne-Castel, N., Lherminier, J., Der, C., Fromentin, J., Houot, V., and Simon-Plas, F. 2008. The plant defense elicitor cryptogein stimulates clathrin-mediated endocytosis correlated with reactive oxygen species production in bright yellow-2 tobacco cells. Plant Physiol. 146:1255-1266.

Leborgne-Castel, N., Adam, T., and Bouhidel, K. 2010. Endocytosis in plant-microbe interactions. Protoplasma 247:177-193.

Leslie, M. E., Lewis, M. W., Youn, J. Y., Daniels, M. J., and Liljegren, S. J. 2010. The EVERSHED receptor-like kinase modulates floral organ shedding in Arabidopsis. Development 137:467-476.

Liebrand, T. W. H., van den Berg, G. C. M., Zhang, Z., Smit, P., Cordewener, J. H. G., America, A. H. P., Sklenar, J., Jones, A. M. E., Tameling, W. I. L., Robatzek, S., Thomma, B. P. H.. J., and Joosten, M. H. A. J. 2013. Receptor-like kinase SOBIR1/EVR interacts with receptor-like proteins in plant immunity against fungal infection. Proc. Natl. Acad. Sci. U.S.A. 110:10010-10015.

Liebrand, T. W., van den Burg, H. A., and Joosten, M. H. 2014. Two for all: Receptor-associated kinases SOBIR1 and BAK1. Trends Plant Sci. 19: 123-132.

Liu, Y., Schiff, M., and Dinesh-Kumar, S. P. 2002. Virus-induced gene silencing in tomato. Plant J. 31:777-786.

Lu, Y. J., Schornack, S., Spallek, T., Geldner, N., Chory, J., Schellmann, S., Schumacher, K., Kamoun, S., and Robatzek, S. 2012. Patterns of plant subcellular responses to successful oomycete infections reveal differences in host cell reprogramming and endocytic trafficking. Cell. Microbiol. 14:682-697.

Luna, E., Pastor, V., Robert, J., Flors, V., Mauch-Mani, B., and Ton, J. 2011. Callose deposition: A multifaceted plant defense response. Mol. PlantMicrobe Interact. 24:183-193.

Mateos, F. V., Rickauer, M., and Esquerré-Tugayé, M. T. 1997. Cloning and characterization of a cDNA encoding an elicitor of Phytophthora parasitica var. nicotianae that shows cellulose-binding and lectin-like activities. Mol. Plant-Microbe Interact. 10:1045-1053.

Miya, A., Albert, P., Shinya, T., Desaki, Y., Ichimura, K., Shirasu, K., Narusaka, Y., Kawakami, N., Kaku, H., and Shibuya, N. 2007. CERK1, a LysM receptor kinase, is essential for chitin elicitor signaling in Arabidopsis. Proc. Natl. Acad. Sci. U.S.A. 104:19613-19618.

Monaghan, J., and Zipfel, C. 2012. Plant pattern recognition receptor complexes at the plasma membrane. Curr. Opin. Plant Biol. 15:349-357.

Mooren, O. L., Galletta, B. J., and Cooper, J. A. 2012. Roles for actin assembly in endocytosis. Annu. Rev. Biochem. 81:661-686.

Morillo, S. A., and Tax, F. E. 2006. Functional analysis of receptor-like kinases in monocots and dicots. Curr. Opin. Plant Biol. 9:460-469.

Nguyen, H. P., Chakravarthy, S., Velásquez, A. C., McLane, H. L., Zeng, L., Nakayashiki, H., Park, D. H., Collmer, A., and Martin, G. B. 2010. Methods to study PAMP-triggered immunity using tomato and Nicotiana benthamiana. Mol. Plant-Microbe Interact. 23:991-999.

Nürnberger, T., Nennstiel, D., Jabs, T., Sacks, W. R., Hahlbrock, K., and Scheel, D. 1994. High affinity binding of a fungal oligopeptide elicitor to parsley plasma membranes triggers multiple defense responses. Cell 78: 449-460.

Ponchet, M., Panabières, Milat M-L., F., Mikes, V., Montillet, J. L., Suty, L., Triantaphylides, C., Tirilly, Y., and Blein, J. P. 1999. Are elicitins cryptograms in plant-oomycete communications? Cell. Mol. Life Sci. 56:1020-1047.

Ricci, P., Bonnet, P., Huet, J. C., Sallantin, M., Beauvais-Cante, F., Bruneteau, M., Billard, V., Michel, G., and Pernollet, J. C. 1989. Structure and activity of proteins from pathogenic fungi Phytophthora eliciting necrosis and acquired resistance in tobacco. Eur. J. Biochem. 183:555-563.

Robatzek, S., Chinchilla, D., and Boller, T. 2006. Ligand-induced endocytosis of the pattern recognition receptor FLS2 in Arabidopsis. Genes Dev. 20:537-542.
Roux, M., Schwessinger, B., Albrecht, C., Chinchilla, D., Jones, A., Holton, N., Malinovsky, F. G., Tör, M., de Vries, S., and Zipfel, C. 2011. The Arabidopsis leucine-rich repeat receptor-like kinases BAK1/SERK3 and BKK1/SERK4 are required for innate immunity to hemibiotrophic and biotrophic pathogens. Plant Cell 23:2440-2455.

Schwessinger, B., Roux, M., Kadota, Y., Ntoukakis, V., Sklenar, J., Jones, A., and Zipfel, C. 2011. Phosphorylation-dependent differential regulation of plant growth, cell death, and innate immunity by the regulatory receptorlike kinase BAK1. PLoS Genet. 7:e1002046.

Shan, L., He, P., Li, J., Heese, A., Peck, S. C., Nürnberger, T., Martin, G. B., and Sheen, J. 2008. Bacterial effectors target the common signaling partner BAK1 to disrupt multiple MAMP receptor-signaling complexes and impede plant immunity. Cell Host Microbe 4:17-27.

Shiu, S. H., and Bleecker, A. B. 2003. Expansion of the receptor-like kinase/Pelle gene family and receptor-like proteins in Arabidopsis. Plant Physiol. 132:530-543.

Spector, I., Shochet, N. R., Blasberger, D., and Kashman, Y. 1989. Latrunculins-Novel marine macrolides that disrupt microfilament organization and affect cell growth: I. Comparison with cytochalasin D. Cell Motil. Cytoskeleton 13:127-144.

Ueda, T., Yamaguchi, M., Uchimiya, H., and Nakano, A. 2001. Ara6, a plant-unique novel type Rab GTPase, functions in the endocytic pathway of Arabidopsis thaliana. EMBO (Eur. Mol. Biol. Organ.) J. 20:4730-4741.

Wang, X., Kota, U., He, K., Blackburn, K., Li, J., Goshe, M. B., Huber, S. C., and Clouse, S. D. 2008. Sequential transphosphorylation of the BRI1/BAK1 receptor kinase complex impacts early events in brassinosteroid signaling. Dev. Cell 15:220-235.

Wendehenne, D., Binet, M. N., Blein, J. P., Ricci, P., and Pugin, A. 1995. Evidence for specific, high-affinity binding sites for a proteinaceous elicitor in tobacco plasma membrane. FEBS (Fed. Eur. Biochem. Soc.) Lett. 374:203-207.

Wu, C. H., Lee, S. C., and Wang, C. W. 2011. Viral protein targeting to the cortical endoplasmic reticulum is required for cell-cell spreading in plants. J. Cell Biol. 193:521-535.

Yan, H. Z., and Liou, R. F. 2006. Selection of internal control genes for realtime quantitative RT-PCR assays in the oomycete plant pathogen Phytophthora parasitica. Fungal Genet. Biol. 43:430-438.

Zhang, W., Fraiture, M., Kolb, D., Löffelhardt, B., Desaki, Y., Boutrot, F. F. G., Tör, M., Zipfel, C., Gust, A. A., and Brunner, F. 2013. Arabidopsis receptor-like protein 30 and receptor-like kinase suppressor of BIR1-1/EVERSHED mediate innate immunity to necrotrophic fungi. Plant Cell 25:4227-4241.

Zhang, L., Kars, I., Essenstam, B., Liebrand, T. W., Wagemakers, L., Elberse, J., Tagkalaki, P., Tjoitang, D., van den Ackerveken, G., and van Kan, J. A. 2014. Fungal endopolygalacturonases are recognized as microbeassociated molecular patterns by the Arabidopsis receptor-like protein RESPONSIVENESS TO BOTRYTIS POLYGALACTURONASES1. Plant Physiol. 164:352-364.

Zipfel, C. 2009. Early molecular events in PAMP-triggered immunity. Curr. Opin. Plant Biol. 12:414-420.

Zipfel, C., Robatzek, S., Navarro, L., Oakeley, E. J., Jones, J. D., Felix, G., and Boller, T. 2004. Bacterial disease resistance in Arabidopsis through flagellin perception. Nature 428:764-767.

Zipfel, C., Kunze, G., Chinchilla, D., Caniard, A., Jones, J. D., Boller, T., and Felix, G. 2006. Perception of the bacterial PAMP EF-Tu by the receptor EFR restricts Agrobacterium-mediated transformation. Cell 125:749-760.

\section{AUTHOR-RECOMMENDED INTERNET RESOURCE}

Sol Genomics Network database: http://solgenomics.net 